\title{
Attention in Character-Classification Tasks: Evidence for the Automaticity of Component Stages
}

\author{
Gordon D. Logan \\ Erindale College, University of Toronto, Mississauga, Canada
}

\begin{abstract}
SUMMARY
Most theories of attention predict that engaging a subject in demanding concurrent activity will increase choice reaction time by an amount proportional to the attention clemands of the choice task. The attention demands of mental operations within the choice task can be assessed by extending Sternberg's additivefactors method. laarameters associated with those processing stages that demand altention will interact with the amount of concurrent activity (i.e., will have greater effects with concurrent activity than without), but parameters associated with attonatic processing stages will not (i.e., the joint effects will be additive).

This analysis was applied to eight character-classification experiments. The classification task was either performed alone or in the retention interval of a short-term memory task which required ordered recall of 7 digits. According to the extended additive-factors methol, the important effects are the interactions of classification-task parameters with memory load.

The first two experiments reported valiclate the method with a memory-search task. Interactions were obtained between memory load and target-set size whose magnitude depended on the amount of practice with specific target sets. Inferences about attention denand and automaticity were shown to be consistent with those drawn from another criterion for altomaticity, based on a different aspect of the data.

The remaining six experiments examined four stages sufficient to perform a visual-search task (encoding, comparison, decision, and response selection). Memory load did not interact with parameters associated with encoding, decision and response-selection stages, and of three parameters associated with the comparison stage (target-set size, array size, and the presence or absence of a bar marker indicating the target's position), only target-set size interacted with memory load (Experiments 1 and 2). It was concluded that most of the processing involved in character classification does not require attention, and this was taken as evidence against models that identify attention with specific processing structures. The results were interpreted as supporting the view that attention is a limited capacity to activate processing structures internally, and the role of attention in preparing, maintaining, and executing mental operations is discussed.
\end{abstract}

Copyright 1978 by the American Psychological Association, Inc. All rights of reproduction in any form reserved. 
Often in everyday behavior we notice that some of the things we do demand more attention than others. In a more analytic mood, we may notice that some components of individual acts seem more demanding than others. These intuitions point to a question of considerable breatth and specificity in more formal studies of attention-the question of the involvement of attention in mental operations.

Mental operations can be considered individually or as components of a series of processing stages involved in producing a

The experiments reported here were conducted at McGill University, Queen's University, and the University of Waterloo; the final report was prepared at Erindale College, University of Toronto. I am grateful for space and facilities so generously given at McGill, Queen's, and Waterloo, and for the stimulation provided by the members of their respective psychology departments.

This research was supported by the following grants from the National Research Council of Canada: Grant A0127 to A. S. Bregman at McGill University; Grant APA-318 to D. J. K. Mewhort at Queen's University; a Principal's Grant to Queen's University; Grant A95 to M. P. Bryden at the University of Waterloo; and Grant APA231 to P. M. Merikle at the University of Water100.

Experiments 3, 6, and 8 were part of a doctoral dissertation submitted by the author to McGill University, May 1975. I am grateful to Al Bregman for supervising the dissertation and providing critical discussion.

Experiment 3 was presented at the 46 th Anntal Meeting of the Eastern Psychological Association, New York, April 1975. Experiments 6 and 7 were presented at the Canadian Psychological Association meeting, Qucbec, P.Q., June 1975. Experiment 4 was presented at the Canadian Psychological Association meeting, Toronto, Ontario, June 1976. Experiments 1 and 2 were presented at the 48th Annual Meeting of the Eastern Psychological Association, Boston, April 1977.

I would like to thank Jane Zbrodoff for conducting Experiments 6 and 8, helping with the data. analysis, and providing critical discussion throughout the development of the ideas, particularly while I was writing the article. The reviewers also suggested many improvements for which I am grateful. Finally, I must acknowledge D. Kahneman's excellent book, Attention and Effort (1973), as a primary source of inspiration.

Requests for reprints should be sent to Gordon D. Logan, Department of Psychology, Erindale College, University of Toronto, Mississauga, Ontario, Canada I.5L 1C6. response. The involvement of attention in specific mental operations is currently controversial. For instance, attentional involvement in operations that prepare a set of target items for comparison with a visual array (Comstock, 1973; Millar, 1975; Posner \& Boies, 1971; Posner \& Klein, 1973) and in subsequent operations that perform the comparison (Atkinson, Holngren, \& Juola, 1969; Estes, 1972, 1974; Gardner, 1973a ; Rumelhart, 1970; Schneider \& Shiffrin, 1977 ; Shiffrin \& Schneider, 1977) has been discussed extensively. The issues are important because of their implications about the control of mental operations during performance. When mental operations are considered as component processing stages, the pattern of attentional involvement across processing, stages becomes important. Attention may be considered either as a property of the structure of the system or as a capacity for activating structures. Since attention as a structural property must have an identifiable locus within the structure, the structural view implies a particular pattern of attentional involvement across stages. By contrast, the capacity view makes no implications about the locus of attentional involvement, since capacity is an energistic property apart from structure.

The present experiments examine the involvement of attention in mental operations underlying performance in a character-classification task. The first two experiments establish and validate a method for inferring attention demands, which focuses on changes in the effects of parameters of the classification task corresponding to changes in the availability of attention. The classification task is performed alone or in the retention interval of a short-term memory task designed to occupy the subject's attention. Interactions between classification-task parameters and the presence or absence of a concurrent memory load are interpreted as inclicating that mental operations associated with those parameters require attention. This method is shown to be both internally consistent and consistent with another current method for inferring attentional involvement. 
The remaining six experiments examine attentional involvement in four processing stages sufficient to perform the vistal-search version of the character-classification task: encoding, comparison, decision, and response selection (Smith, 1968). The pattern of involvement across stages is discussed in terms of structural and capacity models, then the comparison stage is considered in greater detail. The contrast between comparisons in visual search and memory search leads to a discussion of attentional control and suggests that attending might involve the use of capacity to prepare an organized structure to deal most efficiently with an expected stimulus.

\section{Attention, Mental Operations, and Reaction Time}

Structural models. The prototypic structural model includes a linited-capacity channel and a filter. The function of the linitedcapacity channel is to provide task-relevant information to the effectors. The filter prececles the limited-capacity channel in the information flow so that it may select relevant attributes from the stimulus array and thereby reduce the load on the channel. The operation of the filter depends on preliminary processes outsicle the channel that provide the informational basis for selection (Broadbent, 1958; Deutsch \& Deutsch, 1963; Neisser, 1967).

In structural models, the attention demands of mental operations may be characterized by the time and space they require within the limited-capacity channel (Posner $\&$ Keele, Notc 1). Because space is limited, an increase in the clemands on attention will increase the time spent in the channel. A further possibility explored in this article is to reluce the space available by imposing additional, irrelevant demands. With space thus reduced, the same demand should require more time.

In structural models, operations outside the channel require time but not space, and reaction time is the sum of the time requirements insicle and outside of the channel. Reaction time will thus increase as attention demands increase whether or not the demands are relevant to the lask.
Capacity models. Capacity models explain attention in terms of the activation of structures, not in terms of the structures themselves. Attention is identified with the selective activation of mental structures by the allocation of linited central processing capacity. The distinguishing characteristic of these models is the assertion that structure and central processing capacity are separate constituents of the mind: Capacity represents energy, and structure represents the devices that consume energy to produce behavior (Kahneman, 1970, 1973; sce Moray, 1967, and Posner \& Boies, 1971, for related views).

These models generally agree that capacity is not always necessary to activate structures. Structures may be activated internally by the allocation of capacity or externally by the presence of a stimulus on a receptor surface. The attention demands of mental structures thus reflect the extent to which capacity is necessary to activate them. Some automatic structures may only require the presence of a stimulus to be activated; other structures may require capacity as well as stimulation. Theorists have argued for a dimension of automaticity representing all possible degrees of attentional involvement (Kahneman, 1973; LaBerge \& Samnels, 1974; Posner \& Snyder, 1975a).

In capacity models, reaction time is determined by the rate of processing within mental operations and the amount of work requtired of thent. Attention has its effects through the momentary relation between capacity supplied and capacity demanded (Kahneman, 1973). Structural factors impose a limiting rate of processing on an operation that can be approached only when the supply of capacity equals or exceeds the demand. In automatic operations, the demand is essentially zero, so they operate at their limiting rates regardless of the supply. When the supply is less than the demand, as is often the case for operations that require capacity, the rate of processing is slower than the liniting rate by an amount proportional to the deficit. Deficits are produced by increasing the demands of other mental operations to reduce the overall supply. The other mental operations may reside in other 
processing stages of the same task or in other, independent tasks performed concurrently. Concurrent-task performance is especially interesting as both structural and capacity models predict that the load imposed by the additional task will increase processing time by an amount proportional to the demands of the initial task.

Additive-factors method. Under certain conditions, concurrent-task situations may reveal the attention demands of mental operations. The additive-factors method for isolating processing stages in reaction tine data specifies one set of conditions: Sternberg (1969a, 1969b) has argued that mean reaction time represents the sum of the durations of a series of processing stages involved in producing an appropriate response. This implics that two parameters affecting different stages will have additive effects when varied concurrently, whereas parameters affecting the same stage will interact statistically (i.e., the rate of processing of one parameter depends on the value of the other). Thus, when a parameter of one task, identified with a particular processing stage (or mental operation), interacts with a parameter of a concurrent task known to affect the availability of attention, the magnitude of the interaction will indicate the attention demands of the stage (or operation). Additive effects in this situation are important, for they indicate that the operation requires no attention to function. Thus, additivity may be used to iclentify automatic processes. ${ }^{1}$

Before we can interpret clata in this way, we must consider three inherent difficulties with the additive-factors method: First, Sternberg (1969a, 1969b) has raised the possibility that parameters affecting different stages may interact, and parameters affecting the same stage may have additive effects. Thus, additivity and interaction cannot be interpreted without some ambiguity. This is most problematic in exploratory research in which there are no a priori reasons for accepting one interpretation or the other. In the present studies, however, the association of additivity with automaticity and interaction with demand derives from both structural and capacity models of attention. Furthermore, the use of the additive-factors method to define specific processing stages in terms of the particular parameters employed in the studies for the most part replicates previous work (e.g., Smith, 1968; Sternberg, 1969b, 1975).

Statistical considerations provide a second difficulty (Pachella, 1974): The evidence for attomaticity and for the separability of processing stages is the nonsignificance of interactions; the interpretation rests on the acceptance of a null hypothesis. We shall see that the data obtained were sufficiently reliable and regular that the null hypothesis of no interaction secms the best description of the clata. In most cases, the I' ratios for the interaction terms were close to unity, while those for the contributing main effects were highly significant.

A third difficulty derives from Taylor's (1976) stage analysis of reaction time. Taylor argues that subjects may compensate for increased processing time in one stage by reducing processing time in another, and the right amount of compensation may mask a true interaction, producing effects best described as additive. Compensation is well known in the reaction time literature in the form of the speerl-accuracy trade-off (e.g., Pachella, 1974); it is apparent that savings in time can only be bought at the cost of accuracy. Thus, we will look to the error clata for evidence of a compensatory strategy.

1 This discussion assumes that attention can be divided so that both tasks are attended simultaneously. It is possible that attention cannot be divicled and must be switched from task to task. If the switch occurs during the reaction time interval, reaction time will increase by an amount that reflects switching time. If switching time is constant (c.g., Broadbent, 1958), no interactions will be oblained, and the method proposed here is inappropriate (but sec Experiments 1 and 2 ). If switching time increases with the attention demands of both tasks (e.g., JaBerge, 1973a), the parameters, and thus stages, contributing to the attention demands of the classification task can be iclentified: Since processing time and switching time will both increase with the values of these parameters, interactions will indicate that a stage demands attention. Parameters that increase processing time but not switching time may be associated with automatic processing stages. Their effects will be additive with respect to concurrent activity. 


\section{Retention as a Concurrent Task}

Following this application of the additivefactors method, reaction time was measured as a function of parameters of a classification task identified with particular processing stages. On hall of the trials, the attention available to the classification task was reduced by inserting it in the retention interval of a short-term memory task. The attention demands of the stage under study were thus inferred from patterns of interaction and additivity found between memory load and the defining parameters.

Retention was chosen as a concurrent activity for several reasons. First, short-term retention has been treated theoretically as an attention-demanding activity (Atkinson \& Shiffrin, 1968; Broadbent, 1958; Kahneman, 1973). Empirically, it is clear that retention requires attention, since a wide variety of tasks will interfere with it or are interfered with by it when performed concurrently (e.g., Brown, 1958; Crowder, 1967; Johnston, Greenberg, Fisher, \& Martin, 1970; Peterson, 1969; Peterson \& Peterson, 1959; Posner \& Rossman, 1965; Salthouse, 1975; Watkins, Watkins, Craik, \& Mazuryk, 1973). Moreover, the requirement that subjects retain seven or more items during a trial interferes reliably with several visual tasks, including partial and whole report (Henderson, 1972; Scarborough, 1972), detection (Shulman \& Greenberg, 1971), search (Broadbent \& Heron, 1962), and choice reaction time (Shulman \& Greenberg, 1971 ; Shulman, Greenberg, \& Martin, 1971). In general, memory loads of five items or less produce no interference (Darley, Klatzky, \& Atkinson, 1972: Doost \& Turvey, 1971; Turvey, 1966; Wattenbarger \& $\mathrm{Pa}$ chella, 1972), whereas loads of seven items or more produce interference in proportion to load (Shulman \& Greenberg, 1971; Shulman et al., 1971). However, loads of less than five items have been shown to produce interference when the array for the visual task is presented less than $1 \mathrm{sec}$ after the memory load (Chow \& Murdock, 1975, 1976; Connor, 1972).

Retention was also attractive as a concurrent activity because the short-term mem- ory task and the classification task seemed to require different mental operations (Estes \& Taylor, 1964; Gardner, 1973a). Operationally, the memory stinuli (spoken digits or words) were categorically different from the visual stimuli (letters) and involved a separate sensory modality. Thus interference between tasks is not likely to be attributable to overloading some peripheral structure common to both tasks (cf. Brooks, 1968; Kahneman, 1973 ; Norman \& Bobrow, 1975) but rather to overloading attention.

\section{The Experiments}

To review the argument so far, we have seen that most morlels of attention predict that concurrent activity will increase reaction time relative to single-task controls. Extending Sternberg's (1969a, 1969b) additivefactors method, the attention demands of mental operations may be identified: Concurrent activity will interact with parameters associated with processing stages that demand attention but will have additive effects with parameters associated with automatic processing stages. The first two experiments varied target-set size and decision type (yes or no) in the memory-search version of the character-classification task, and the task was performed both alone and in the retention interval of a concurrent shortterm memory task. Patterns of interaction and additivity obtained between target-set size and concurrent memory load were sufficient to validate the present extension of the additive-factors method. Further, the associated inferences of attention demand and automaticity were corroborated by another criterion for automaticity (i.e., Posner \& Snyder, 1975a).

The method thus validated was applied in the next six experiments to identify the attention demands of parameters associated with encoding, comparison, decision, and response-selection stages of the visual-search version of the character-classification task.

\section{General Method}

This section describes aspects of the method common to all experiments. When specific experiments 
depart from the general method, the departure will be noted in the method sections for those experiments.

\section{Subjects}

Each experiment involved paid subjects who reported normal or corrected-to-normal vision. Subjects were tested individually in $1-\mathrm{hr}$ sessions. The number of subjects in each experiment appears in column 7 of Table 1 , and the number of sessions each subject completed appoars in column 6 .

\section{Apparatus and Stimuli}

In all experiments, the classification task required decisions about visually presented arrays. In the memory-search experiments (1 and 2) the arrays contained single letiers, and in the visualscarch experiments ( 3 through 8 ) the arrays contained 4, 8, and 12 different letters. Details of the composition of the arrays may be found in the method section of Experiment 1 for the menorysearch studies and of Experiment 3 for the visualsearch studies.

In all experiments, the arrays were made of black letters on white cards and were exposed in a tachistoscope. The exposure of each array was preceded and followed by a fixation field containing a small black dot in the center of a white field. The luminance of fixation and stimulus field was matched for each experiment; the luminance values appear in column 1 of Table 1.

In all experiments, there was a constant delay between the initiation of the tachistoscope timers and the onset of the array. The sharp click of the switch initiating the timers was audible and served as a warning signal. The durations of the delays (foreperiods) appear in column 2 of Table 1.

After the foreperiod, the arrays were exposed for the durations appearing in column 3 of Table 1. The fixation field returned when the arrays terminated and remained on for the remainder of the retention interval. At the end of the retention interval, the fixation field was turned off for 500 msec as a signal for the subject to begin recall. The intervals between the termination of the array and the onset of the signal to recall are given in column 4 of Table 1 . Note the value of zero for cue delay in Experiment 3. Here, recall was immediate, so no cue was given-the fixation ficld returned after the array and remained on until the array was exposed on the next trial.

Reaction time was measured in msec from the onset of the array, using a digital timer. The timer was started by the tachistoscope timers and stopped when the subject pressed one of two buttons attached to microswitches mounted on a panel in front of him or her (all experiments except 6 and 8 ) or spoke into a microphone, thus closing a voice-activated relay (Experiments 6,7 , and 8 ). Pressing each button illuminated a separate light visible only to the experimenter so that accuracy could be monitored.

In all except Experiment 8, the memory stimuli were strings of 7 unique digits presented at an approximate rate of $.75 \mathrm{sec}$ per digit (the memory stimuli for Experiment 8 will be described later). In Experiment 3 the digits were presented orally, while in all other experiments they were recorded and played back through a speaker. A different

Table 1

Parameter Values for each Experiment

\begin{tabular}{|c|c|c|c|c|c|c|c|c|}
\hline \multirow[b]{3}{*}{$\begin{array}{l}\text { Experi- } \\
\text { ment }\end{array}$} & \multirow[b]{3}{*}{$\begin{array}{c}\text { Characteristic } \\
\text { variable }\end{array}$} & \multicolumn{7}{|c|}{ Parameter } \\
\hline & & 1 & 2 & 3 & 4 & 5 & 6 & 7 \\
\hline & & $\begin{array}{l}\text { Lumi- } \\
\text { nance } \\
\text { (ft L.) }\end{array}$ & $\begin{array}{l}\text { Fore- } \\
\text { period } \\
\text { (msec) }\end{array}$ & $\begin{array}{l}\text { Exposure } \\
\text { (msec) }\end{array}$ & $\begin{array}{l}\text { Delay of } \\
\text { recall } \\
\text { cue } \\
\text { (sec) }\end{array}$ & $\begin{array}{l}\text { Practice } \\
\text { (trials) }\end{array}$ & Sessions & $\begin{array}{l}\text { Sub- } \\
\text { jects }\end{array}$ \\
\hline 1 & Target-set size & 14 & 500 & 500 & 4.5 & $\begin{array}{l}8 \text { per set size } \\
\text { per day }\end{array}$ & $6-7$ & 6 \\
\hline 2 & Target-set size & 14 & 500 & 500 & 4.5 & $\begin{array}{l}8 \text { per set size } \\
\text { per day }\end{array}$ & 6 & 6 \\
\hline 3 & Bar marker & 8 & 100 & 500 & 0 & 0 & 4 & 8 \\
\hline 4 & Mask & 29 & 500 & 1,500 & 4 & 10 & 4 & 8 \\
\hline 5 & Yes-no decision & 8 & 500 & 500 & 5 & 10 & 1 & 16 \\
\hline 6 & $\begin{array}{l}\text { Stimulus-response } \\
\text { compatibility }\end{array}$ & 8 & 500 & 500 & 5 & $\begin{array}{l}10 \text { per } \\
\text { compatibility } \\
\text { condition }\end{array}$ & 4 & 8 \\
\hline 7 & Response type & 8 & 500 & 500 & 5 & $\begin{array}{l}10 \text { per } \\
\text { response type }\end{array}$ & 4 & 8 \\
\hline 8 & Memory load & 8 & 500 & 500 & 5 & 10 & 1 & 16 \\
\hline
\end{tabular}


list was presented on each memory-load trial, and each day involved a new set of lists. Fach list was preceded by a warning signal (YOUR NEXT LAIST Is) and followed by a ready signal (READY), which occurred about $1.5 \mathrm{sec}$ after the last digit in each string. Since the arrays were typically exposed about $1 \mathrm{sec}$ after the ready signal, the retention interval was roughly $3 \mathrm{sec}$ in Hxperiment 3 and roughly $8 \mathrm{sec}$ in all others (i.e., $2.5 \mathrm{sec}$ plus the sum of columns 3 and 4 of Table 1 ).

\section{I'rocedure}

In all experiments, trials involving a memory load consisted of the following sequence of events (a) the presentation of the memory list; (b) the presentation of a verbal ready signal; (c) the subject's affirmative reply to the ready signal, indicating that the fixation point was in sharp focus; (d) the foreperiod between the click of the initiating switch and the exposure of the array; (e) the exposure of the array; (f) the subject's response to the array; (g) a delay and the dark interval signalling recall; and (h) the subject's recall of the 7 digits in the order in which they were ptesented. Trials not involving a memory load omitted events (a) and (h).

Experiments 1 and 2 manipulated target-set size (1, 2, or 4 letters), decision type (yes or no), and memory load ( 0 or 7 digits). Each session consisted of six blocks, one for each factorial combination of target-set size and memory load, and decision type varied randomly within blocks.

The primary variables in the remaining experiments (except Experiment 8) were array size (4, 8 , or 12 letters), menory load ( 0 or 7 digits), and a parameter (two levels) defining the stage under study. Memory-load conditions and values of the defining parameters were combined factorially and run in separate blocks. Each session consisted of four blocks, one for each combination, in which array size varied randomly.

The orders of conditions across subjects each day and within subjects over days were determined by balanced Latin squares. In Ixperiments 1 and 2 arrays within blocks (and thus decisiontype conditions) were presented in two (inverse) orders, and subjects alternated orders over days, half beginning with one (i.e., $A B \triangle B$ ) and half with the other (i.c., $B A B A$ ). Memory-load conditions alternated over blocks and subjects in a similar fashion, and assignment of decision types to response buttons was balanced over subjects as well. Becanse of the small sample size (Table 1, column 7), these assignments were necessarily confounded.

In Experinent 3 the arrays (and thus arraysize conditions) were presented to all subjects in the same order each day. Experiments 4 through 8 used two orders of arrays, the one used in Experiment 3 and its inverse, alternating over subjects and days as in Experiments 1 and 2. Assignment to these orders was orthogonal to the assignument to orders of memory-load and defining-parameter conditions. In experiments that involved manual responses, the assignment of hands to response buttons was balanced across subjects. This assignment was always orthogonal to the assignment to orders of memory-load and defining-parameter conditions, and wherever possible, orthogonal to the assignment to orders of arrays.

Each session consisted of 144 trials clivided into six 24-trial blocks in Experiments 1 and 2, and into four 36 -trial blocks in Experiments 3 through 8. The number of sessions per subject in each experiment appears in column 6 of Table 1 . In experiments involving more than one session per subject, each subject served in one session per day at the same time each day plus or minus $1 \mathrm{hr}$. Whenever possible, sessions werc run on consecutive days, and no more than 2 days elapsed betwecn consecutive sessions.

Instructions first described the visual task, explaining the procedure and describing the experimental conditions, using examples where appropriate. Subjects were told to respond to the array as quickly as possible withont making errors. Thus an example of a digit string was given, and the seluence of events on a memory-load trial was described. Subjects were instructed to concentrate on the memory task during memory-load trials. They were told that it was the most important task and that they should optimize their performance on it. Thus, according to instructions, the memory task was primary and the visual task was secondary.

In general, the instructions were followed by a series of practice trials, then testing began. The number of practice trials in each experiment appears in column 5 of Table 1. J'ractice was given each day in Experiments 1 and 2 but only on the first day in the remaining experiments; the sequence of conditions for that day was described, and testing began after a brief delay.

Subjects were not given feedback regarding their speed or accuracy in the visual task. In the memory task of Experiments $]$ and 2, subjects were told the number of digits they recalled correctly after each trial, but no feedback about recall accuracy was given in the remaining experiments.

\section{Data Analysis for the Visual Task}

In cach session, each subject completed 12 trials for each combination of visual-task conditions. Mean reaction times for correct responses in each condition were computed for each session for each subject. Reaction times exceeding $1,900 \mathrm{msec}$ were scored as errors to reduce skew it the individual reaction time distribution. These means were submitted to a four-way within-subjects analysis of variance, with target-set size, decision type, memory load, and days as factors in Experiments 1 and 2 , and with array size, memory load, definingparameter conditions, and days (where appropriate) as factors in Experiments 3 through 8 . The mean error rate (in proportions) is reported 
for each condition, but the error iregtrencies were generally too low for statistical analysis.

\section{Data Analvis for the Memory Task}

In each session each subject was recuired to recall 12 lists of 7 digits in each combination of visual-task conditions. The mean number of digits recalled in correct order in each list was computed for each subject in each condition. These means were then subjected to a three-way within-subjects analysis of variance, with target-set size, decision type, and days as factors in Experiments 1 and 2 , and with array size, defining-parameter conditions, and days (where appropriate) as factors in Experiments 3 through 8 .

\section{Critcria for Automaticity}

The experiments reported in this section examined attentional involvement in comparison and decision stages of a memorysearch task. Patterns of interaction and additivity were obtained between memory load and target-set size that, first, valiclated the extended arlditive-factors method as a technique for assessing attentional involvement by demonstrating the development of atutomaticity with practice and, second, provided new insight into the comparison stage, particularly in contrast with related findings in the following experiments on visual search. Since the technique must be validated before it can be used inferentially, this section will focus on validation, and discussion of implications for the nature of the comparison stage will be cleferred until later (see Comparison Stage Revisited, p. 58).

The mennory-search task is an appropriate vehicle for validation, as it allows the assessment of automaticity by three different criteria. The task itself requires that the subject decide whether or not an array contains a member of a set of target items presented earlier, and in general, reaction time increases linearly with the size of the target set with the same slope for both decision outcomes (for reviews, see Nickerson, 1972; Sternberg, 1969a, 1969b, 1975).

The first criterion identifies automatic search with zero slope in the target-set-size function. It was first proposed by Neisser and his colleagues (Neisser, Novick, \& Lazar, 1963) upon finding that with enough practice subjects could search for 10 targets as quickly as for 1 (i.e., zero slope). They argued that search was antomatic, since decisions abont individual targets seened inclependent of one another. Subsequent replications have revealed sufficient conditions for approximately this effect; extended practice with nested target sets and consistent mapping of stimuli onto responses will produce slopes that approach zero but rarely reach it (Corballis, Roldan, \& Zbrodoff, 1974; Graboi, 1971; Kristofferson, 1972a, 1972b; Neisser, 1974; Schneider \& Shiffrin, 1977). Atrtomaticity, by this criterion, secms a rare event, and although Shiffrin and Schneider (1977) have used it to butild a general theory of attentional control, it applies directly only to the comparison stage of classification tasks.

Posner and Snyder (1975a) have proposed more general criteria for antonaticity: They arguc that automatic structures are activated without intention and without interference from concurrent activity in other structures. The latter is essentially the extension of the additive-factors method developed earlier, and it is readily applicable to memory search. The amount of interference may be assessed from the magnittde of interactions between memory load and parameters of the scarch task-target-set size in particular. The former may be applied to the memory-search task as well: If a stimt1us attomatically elicits a tendency toward a response onto which it has been consistently mapped, the tendency showld be elicited even when the mapping is changed so that the stimulus now requires the opposite response, and it should inhibit responses based on the new mapping. Similar interference is found when stibjects name the color of the ink in which a conflicting color word is written (Stroop, 1935; for a review see Dyer, 1973). Attention is directed elsewhere, yet the representation in permanent memory is activated automatically by its characteristic stimulus (Keele, 1972).

\section{Experiments 1 and 2}

Experinents 1 and 2 were designed to search for agreement among the three cri- 
teria for automaticity. In Experiment 1 , sthbjects searched one list of 1-, 2-, and 4-letter target sets for 6 days, then switched to another list in which half of the no items had been yes on the previous list. ()n half of the trials each day, the talsk was periormed in the rentention interval of a short-term memory task requiring ordered recall of 7 digits. According to the first criterion, search will be antomatic when the slope of the target-set-size function reaches zero. According to the second, search will he auto matic when monory load no longer increases the slope of the target-set-size function (i.e., when memory load and target-set sizc no longer interact), and according to the third, search will have beconse automatic if items that had received yes responses consistently for 6 days take longer to respond "no" to than other items, when the mapping is changed on the 7 th day.

Experiment 2 was an exact replication of Experiment 1 except that a different list of target sets was used each day. Its purpose was to provide baseline conditions under which attomaticity should not develop, against which to cvaluate the effects in Experiment 1.

\section{Method}

There were several departures from the general method. First, subjects were run for at least six 1-hr sessions on consecutive days (sce General Method). Second, subjects received feedhack about their memory performance. At the end of each trial they were told the number of digits they recalled correctly and the positions and nature of their

Table 2

Positive and Negative Target Sets Used in lixperiment 1 (Lists 1 and 2) and Experiment 2 (Lists 1-6)

\begin{tabular}{ccccc}
\hline \multicolumn{4}{c}{$\begin{array}{c}\text { Positive } \\
\text { target-set size }\end{array}$} & \\
\cline { 2 - 5 } List & 1 & 2 & 4 & Negative set \\
\hline 1 & H & NR & SKXP & BCIFGJLMTVYZ \\
2 & D & BJ & FZTG & CHKLMNPRSVWY \\
3 & M & CV & LWYH & BDFGKNPQRSXZ \\
4 & T & XK & RBGW & CDFILMNPSVYZ \\
5 & $Z$ & LF & CMVY & IGHKNPQRSTWX \\
6 & $\mathrm{~S}$ & PM & DQNC & BFGKLRTVWXYZ \\
\hline
\end{tabular}

crrors. The feedback was to ensure concentration on the memory task. Third, subjects were not required to reply to the verbal ready signal presented before each trial (i.e., Fvent $c$ of the general procedure was omitted). Fourth, subjects were given 8 practice trials whenever target-set size changed, and practice was given every day.

Apparatus and stimuli. A Scientific Prototype three-field tachistoscope (Model GB) was used to expose the arrays. Each array consisted of a single black capital letter (Letraset \#287) mounted centralty on white cards so as to appear on top of the fixation point. Each letter subtended about 11' $\times 11^{\prime}$ of visual angle. 'emporal and luminance parameters are given in Table 1 .

The target sets were drawn from a restricted alphabet of 21 letters $(A, E, I, O$, and $U$ were excluded). Positive sets (those recuiring yes responses) contained 1,2 , or 4 different letters. The same 12-letter negative set was used for each positive set in a list. Six different lists were prepared (sec Table 2). In Experiment 1, one list (List 1) was used for the first 6 days, and 4 subjects returned for a 7 th session, which used List 2 . (Note that half of the no items in List 2 were yes items in List 1.) In Experiment 2, all 6 lists werc used. Fach subject dealt with a different list each day, and each day each subject had a different list. Assignment of lists to subjects and days was hased on a $6 \times 6$ balanced Latin squarc. Since List 2 did not follow 1 ist 1 consistently in this experiment, List 2 data can be compared with those of Experiment 1 as a control for specific practice with $\mathrm{J}$ ist 1.

Procedure. Each session consisted of 144 trials divided into six blocks of 24 trials, one for each combination of target-set-size and memory-load conditions. Each larget-set size was tested for two consecutive blocks, one with memory load and one without. The order of memory-load and no-memory-load conditions varied within subjects over days and between subjects within days. Over days, each subject reccived all six possible orders of target-set-size conditions, and each day each of the six subjects received a different order. Decision outcome (yes or no) varied randomly within blocks. In each block there were 12 yes and 12 no responses.

\section{Results and Discussion: Experiment 1}

$V$ isual task. Mean reaction times for each combination of target-set-size, decision-outcome, and memory-load conditions (excluding Day 7) are displayed in Figure 1. Each point in the figure is based on 432 observations. In an analysis of variance performed on mean reaction times, significant effects were found for days, $F(5,25)=15.00$, $p<.01$, target-set size, $F(2,10)=80.61$, $p<.01$, and decision outcome, $F(1,5)=$ 


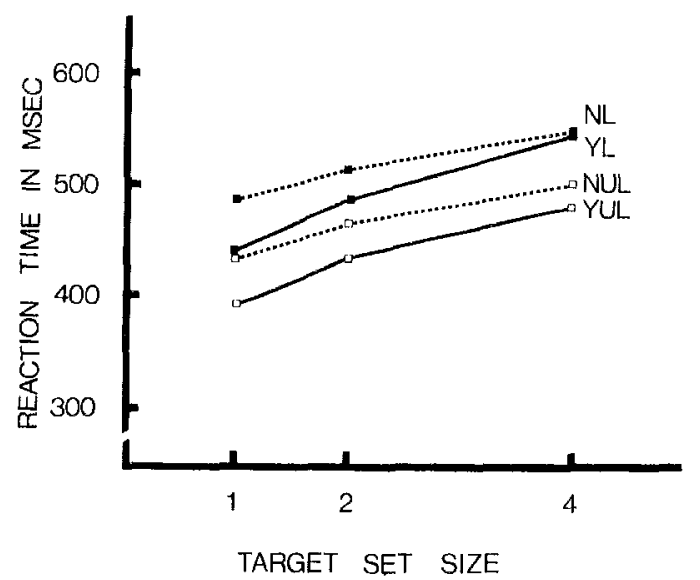

Figure 1. Mean reaction times in the visual task of Experiment 1 as a function of target-set size. (Decision-type and memory load conditions are parameters: $\mathrm{Y}=$ yes; $\mathrm{N}=$ no; $\mathrm{I}$ = memory load ; $\mathrm{UL}=$ no memory load.)

7.45, $p<.05$. Reaction time decreased over days, increased with target-set size, and was longer for no than for yes decisions.

Though a concurrent memory load increased reaction time overall by $54 \mathrm{msec}$, the effect was not significant, $F(1,5)=4.21$, $p>.05$. However, the interaction of memory load with days was significant, $F(10,50)$ $=4.40, p<.01$, indicating a large initial effect (109 $\mathrm{msec}$ ) which diminished over days.

The interaction between memory load and target-set size was not significant, $F(2,10)$ $<1$, but the three-way interaction between memory load, target-set size, and days was, $F(10,50)=3.97, p<.01$. The meaning of this interaction and the one between targetset size and days, $F(10,50)=4.40, p<$ .01 , may be better expressed in terms of the slopes of the functions relating reaction time to target-set size. Slopes and intercepts of the best-fitting linear functions were computed each day for each subject individually, and the mean values appear, respectively, in the top and bottom panels of Figure 2. Note that an apparent main effect in the slope data is equivalent to a linear interaction with target-set size.

Figure 2 shows a general reduction in slope over days, reaching an asymptotic value of about $20 \mathrm{msec}$ per item on Days
4, 5, and 6. According to the zero-slope criterion, search had not become automatic after 6 days of practice. The figure also shows that memory load and target-set size interacted at early stages of practice, but not later on. Considering the yes data, the memory-load slopes were substantially higher than no-memory-load slopes for Days 1, 2, and 3, but were slightly lower on Days 4, 5 , and 6 . In the no data, memory-load slopes were only higher than no-memory-load slopes on Day 1. According to the extended additive-factors logic, the interaction early in practice indicates that search demanded attention initially, and the gradual transition to additivity indicates the development of automaticity with practice.

To see whether this attomaticity had developed from specific practice, four su1bjects were induced to return for a 7 th day to be tested with a different list of target sets. Their data, plotted above Day 7 in Figure 2, show elevated memory-load slopes at least for yes decisions. For no decisions, the nomemory-load slopes remained higher than the memory-load slopes on J)ay 7 , continuing a trend that had developed on Day 4. The data, then, provide some support for the hypothesis that automaticity had developed from specific practice. The hypothesis re-

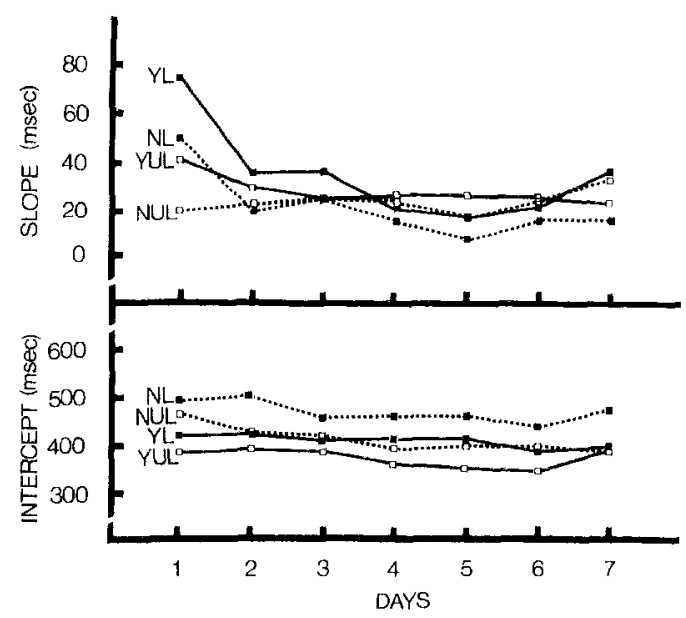

Figure 2. Mean slopes (top panel) and intercepts (bottom panel) of the best-fitting linear functions of target-set size from the reaction time data from Experiment 1. (Decision-type and memory-load conditions are parameters: $Y=$ yes; $N=$ no; $L=$ memory load ; UL = no memory load.) 
Table 3

Mean Reaction Times (in msec) and Proportions of lirrors to No Items from List 2

\begin{tabular}{|c|c|c|c|c|c|c|c|c|}
\hline \multirow[b]{4}{*}{ Type of item } & \multicolumn{8}{|c|}{ Memory load } \\
\hline & \multicolumn{4}{|c|}{ Experiment 1 , Day 7} & \multicolumn{4}{|c|}{ Experiment 2} \\
\hline & \multicolumn{2}{|c|}{0 digits } & \multicolumn{2}{|c|}{7 digits } & \multicolumn{2}{|c|}{0 digits } & \multicolumn{2}{|c|}{7 digits } \\
\hline & $\mathrm{RT}$ & $\begin{array}{l}\text { Error } \\
\text { rate }\end{array}$ & R'T & $\begin{array}{c}\text { Firror } \\
\text { rate }\end{array}$ & $\mathrm{RT}$ & $\begin{array}{l}\text { Error } \\
\text { rate }\end{array}$ & $\mathrm{RT}$ & $\begin{array}{l}\text { Error } \\
\text { rate }\end{array}$ \\
\hline Old yes & 486 & .04 & 537 & .10 & 495 & .03 & 584 & .02 \\
\hline Old no & 441 & .01 & 469 & .00 & 490 & .01 & 600 & .02 \\
\hline
\end{tabular}

Note. Old-yes items were yes items on List 1 , and old-no items were no items on I ist 1 . RT $=$ reaction time.

ceives a more stringent test in Experiment 2 .

Clearly, these two criteria for antomaticity provide conflicting interpretations of the slope data; the zero-slope criterion suggests that automaticity had not been obtained, while the additive-factors criterion suggests that automaticity had developed by Day 4 . The data from Day 7 provide a test by the third criterion of automaticity, unintentional activation.

The no items from Day 7 (List 2) were divided into old-yes and old-no items according to their assigned mapping on Days 1 to 6 (List 1 ). Mean reaction times to these items with and without a memory load are displayed in Table 3.

According to the unintentional-activation criterion, old-yes reaction times should be longer than old-no reaction times if auto-

\section{Table 4}

Proportion of Errors in the Visual Task and Recall Accuracy (in parentheses) in the Memory Task (Across Subjects and Days) as a function of Visual-Task Conditions in Experiment 1

\begin{tabular}{clcc}
\hline & \multicolumn{3}{c}{ Target-set size } \\
\cline { 2 - 4 } $\begin{array}{c}\text { Decision } \\
\text { type }\end{array}$ & \multicolumn{1}{c}{1} & 2 & 4 \\
\hline Yes & & & \\
0 digits & .02 & .04 & .04 \\
7 digits & $.02(6.26)$ & $.05(6.29)$ & $.08(6.22)$ \\
No & & & \\
0 digits & .02 & .02 & .05 \\
7 digits & $.02(6.33)$ & $.05(6.23)$ & $.05(6.25)$ \\
\hline
\end{tabular}

maticity had developed over the 6 days of practice with List 1 . On the average, oldyes reaction limes were $56 \mathrm{msec}$ longer than old-no reaction times, and the difference was significant, $t(3)=2.44, p<.05$, one-tailed. The data thus indicate that automaticity had developed, corroborating the interpretation of the slope data given the additive-factors criterion.

The error data from Day 7 are presented in Table 3 ; the error data from Days 1 to 6 appear in Table 4 . In general, the error data reflect the patterning of the reaction time data.

Memory task. The mean numbers of digits recalled in correct order for each combination of target-set-size and decisionoutcome conditions also appear in Table 4. The only significant effect in an analysis of variance performed on these data was that of days, $F(5,25)=3.89, p<.01$, indicating improvement in recall accuracy with practice.

\section{Results and Discussion: Experiment 2}

Visual task. Mean reaction times for cach combination of target-set-size, decision-outcome, and memory-load conditions are displayed in Figure 3. Each point in the figure is based on 432 observations. The only significant effects in an analysis of variance performed on mean reaction times were the main effects of days, $F(5,25)=3.25, p$ $<.05$, target-set size, $F(2,10)=85.16, p$ $<.01$, and decision outcome, $F(1,5)=$ $29.83, p<.01$. Again, reaction time de- 
creased over days, increased with target-set size, and was larger for no decisions than for yes decisions.

Overall, the requirement that stbjects retain 7 digits increased reaction time by 97 msec, but the memory-load main effect was not significant, $F(1,5)=4.82, p>.05$, and although the Memory Load $\times$ TargetSet Size interaction appears substantial in Figure 3, it was not significant either, $F(2$, $10)=3.45, p>.05$. However, there were large individual differences in the memoryload main effect (ranging from -1 to 299 msec), which when combined with the small sample size ( six subjects), may have inflated the error term and masked the interaction. To remove this source of influence, slopes and intercepts of best-fitting linear functions were computed for each subject each day, and the slopes were submitted to an analysis of variance. Again, a main effect in the slope data represents a linear interaction with target-set size.

Mean slopes and intercepts in each condition each day appear, respectively, in the top and bottom panels of Figure 4 . The slope data in the figure show a consistent interaction of memory load with target-set size: The memory-load slopes for both decision outcomes are consistently higher than the no-memory-load slopes each day.

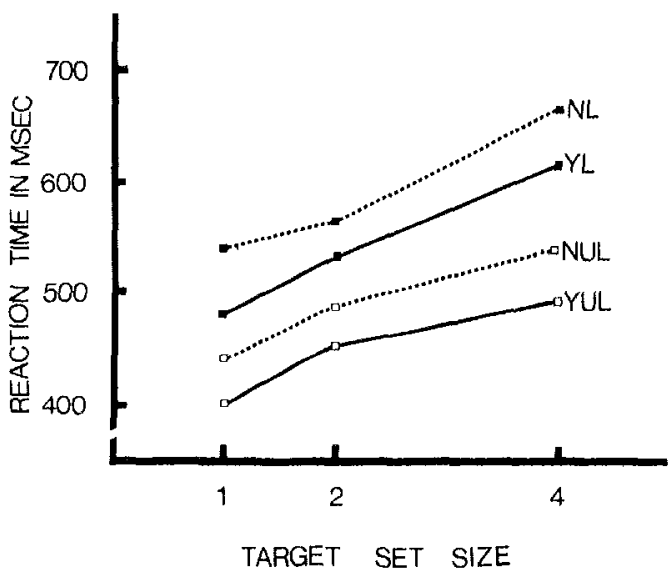

Figure 3. Mean reaction times in the visual task of Experiment 2 as a function of target-set size. (Decision-type and memory-load conditions are parameters: $Y=$ yes; $N=$ no; $L=$ memory load; $\mathrm{UL}=$ no memory load.)

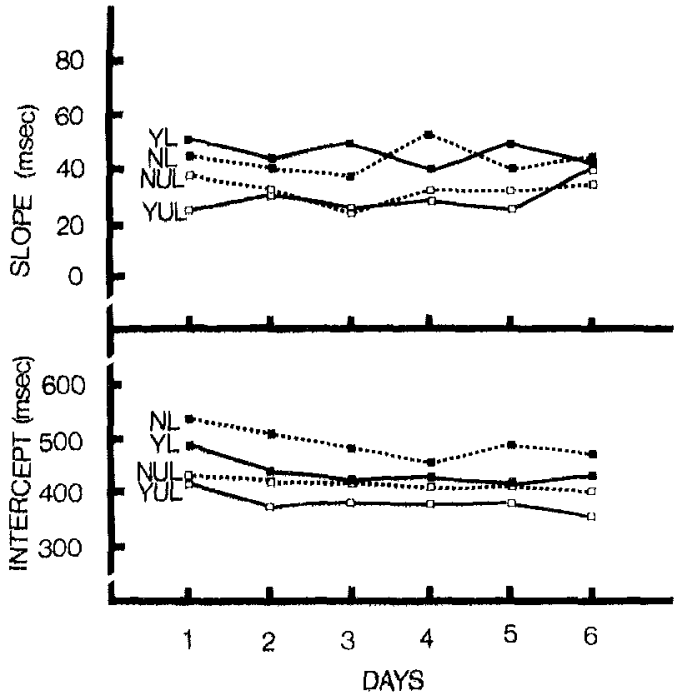

Fignte 4. Mean slopes (top panel) and intercepts (bottom panel) of the best-fitting linear functions of target-set size from the reaction time data from Experiment 2. (Decision-type and memory-load conditions are parameters: $\mathrm{Y}=$ yes; $\mathrm{N}=$ no; $\mathrm{L}=$ memory load; UL $=$ no memory load.)

This is supported by the significant memoryload main effect in the analysis of variance on the slope data, $F(1,5)=8,28, p<.05$, which was the only significant effect in the analysis.

According to both the zero-slope criterion and the additive-factors criterion, the data indicate that search was not automatic. The slopes were consistently above zero, and the memory-load slopes were consistently greater than the no-memory-load slopes, The unintentional-activation criterion may be applied to the List 2 no data presented in Table 3, divided into old-yes and old-no items according to their mapping on List 1 . Since subjects in this experiment had not received extended practice with List 1 before they were tested with List 2 , it is not likely that old-yes items would automatically elicit com: peting response tendencies, so old-yes and old-no reaction times should be approximately equal. In fact, old-no reaction times were 6 msec longer than old-yes, and the difference was not siguificant, $t(5)<1$. According to the unintentional-activation criterion, automatic search had not developed. 
Table 5

Proportion of Errors in the Visual Task and Recall Accuracy (in parentheses) in the Memory Task (Across Subjects and Days) as a Function of Visual-Task Conditions in lixperiment 2

\begin{tabular}{|c|c|c|c|}
\hline \multirow{2}{*}{$\begin{array}{c}\text { Decision } \\
\text { type }\end{array}$} & \multicolumn{3}{|c|}{ Target-set size } \\
\hline & 1 & 2 & 4 \\
\hline \multicolumn{4}{|l|}{ Yes } \\
\hline 0 digits & .01 & .02 & .06 \\
\hline 7 digits & $.01(6.52)$ & $.05(0.59)$ & $.07(6.47)$ \\
\hline \multicolumn{4}{|l|}{ No } \\
\hline 0 digits & .02 & .02 & .02 \\
\hline 7 digits & $.01(6.53)$ & $.02(6.51)$ & $.03(6.55)$ \\
\hline
\end{tabular}

Thus, the three criteria agree in assessing attentional involvement in search in Experiment 2 . The tests by the additive-factors and unintentional-activation critcria confirm the earlier conclusion that specific practice is necessary to develop automaticity.

The error data are presented in Tables 3 and 5 .

Memory task. The mean number of digits recalled in correct order for each combination of target-set-size and decision-outcome conditions appear in Table 5. Again, the only significant effect in the analysis of variance performed on these data was that of days, $F(5,25)=15.94, p<.01$, indicating an improvement in recall accuracy with practice.

\section{Discussion of Experiments 1 and 2}

Experiments 1 and 2 have shown an interaction between concurrent memory load and target-set size that varies in magnitude according to the degree of practice with specific target sets. Three days of specific practice were enough to eliminate the interaction. These findings bear on the validation of the extended additive-lactors logic as a method for assessing attentional involvement in mental operations. First, they show that the method is internally consistent in that additivity and interaction both occur in real clata and their pattern can be interpreted meaningfully. In particular, the diminishing interaction in Experiment 1 sug- gests the development of automaticity over days. Second, the inferences based on these findings agree with those based on another criterion for automaticity - the unintentionalactivation criterion - which was assessed from different aspects of the data (i.e., the difference between old-yes and old-no reaction times). When search had become attomatic by the additive-factors criterion, there was evidence of unintentional activation (Experiment 1); when search required attention by the addlitive-factors criterion, there was no evidence of unintentional activation (Experiment 2).

The disagreement between these two criteria and the zero-slope criterion is interesting. According to the zero-slope criterion, search was not automatic in either experiment. This difference may reflect two distinct concepts of automaticity. In this article and elsewhere (Kahneman, 1973; I a Berge \& Sanuels, 1974; Posner \& Snyder, 1975a, 1975b), automaticity refers to the withdrawal of attentional control over mental structures. In other contexts, automaticity refers to a change in the composition of structures assembled to perform a task in favor of more efficient performance (Kolers, 1975). The additive-factors and unintentional-activation criteria refer explicitly to the former concept (see Posner \& Snyder, 1975a). In fact, the aclditive-factors method assumes that the composition of task-relevant structures does not change when memory load is manipulated. By contrast, the zero-slope criterion seems to refer to a change in the composition of structures (Neisser, 1974; Shiffrin \& Schneider, 1977). Since we are concerned directly with the involvement of attention in the activation of mental structures, the disagreement with the zero-slope criterion is of no consequence, however interesting it may be in other contexts. The experiments have shown that the extended additive-factors method provides a valid assessment of attentional involvenent, so we may use it to investigate the demands of other processing stages.

The remaining experiments examine encoding, comparison, decision, and responseselection stages of the visual-search version of the classification task. Since these repre- 
sent an assembly of operations sufficient to produce a stimulus-controlled response (Smith, 1968; Sternberg, 1969a, 1969b), we may construct a relatively complete picture of the nature and loci of the demands of the task.

\section{The Comparison Stage}

In general, classification tasks require the subject to decide whether or not an array of items contains one or more of a set of target items presented some time earlier (for a review, see Nickerson, 1972). Logically, the decision depends on the outcome of comparisons between the items in the array and the target set, so it is natural that the comparison stage has received the lion's share of empirical and theoretical attention. The stage is ustally identified with two parameters, the number of items in the array (array size) and the number in the target set.

Experiments that vary target-set size usually employ single-item arrays and are said to study memory search; experiments that vary array size usually involve single-item target sets and are said to study visual search. It is not clear whether the two types of search involve different comparison processes. The strong interactions obtained between array size and target-set size may suggest they do (Briggs \& Blaha, 1969; Briggs \& Johnsen, 1973; Briggs \& Swanson, 1970; Johnsen \& Briggs, 1973; Nickerson, 1966; Schneider \& Shiffrin, 1977; Sternberg, Note 2), but these effects may be explained as well by models that assume separate comparison processes (e.g., Townsend \& Roos, 1973) as by models that assume a single process (e.g., Schneider \& Shiffrin, 1977). I will offer an opinion at a later point (see Comparison Stage Revisited), but for now, let us consider each task separately. The focus on visual comparison in the remaining experiments reflects my initial interest in visual search (see Logan, 1975).

Two versions of the visual-search task appear in the literature, yes-no and forced choice. The yes-no version requires a yes response if a target item appears in the array, a no response otherwise. The forced- choice version involves two target items, each associated with a separate response. One of the targets is presented on each trial, and the task is to decide which of the two it was. The forced-choice version offers twice as many observations per data point in the same number of trials, and so it was chosen over yes-no in the present experiments.

There has been some speculation that forced choice may involve different processes than the yes-no version (Holmgren, 1974b), but the supportive evidence is not compelling (cf. Experiment 5). On the contrary, the similarities are quite striking: Reaction time increases with array size in both yesno (Atkinson et al., 1969; Egeth, Atkinson, Gilmore, \& Marcus, 1973; Novik \& Katz, 1971; Schneider \& Shiffrin, 1977; Townsend \& Roos, 1973) and forced-choice versions (Estes, 1972; Estes \& Wessel, 1966; Holmgren, 19741); Logan, 1976), and when the number of items relevant to the comparison process is reduced to one by indicating the position of the target with a bar marker, reaction times are reduced in proportion to array size in both yes-no (Holmgren, 1974a) and forced-choice versions (Logan, Withey, \& Cowan, 1977). Indeed, the interaction between array size and the presence or absence of a bar marker common to both versions suggests that they do, in fact, affect the same comparison stage.

\section{Experiment 3}

In this experiment, the comparison stage was defined by two parameters, array size and the presence or absence of a bar marker, both of which determined the number of items relevant to the comparison process. The visual task was performed both alone and in the retention interval of a memory task that required ordered recall of 7 digits. The attention demands of the comparison stage were to be indicated by interactions between memory load and the defining parameters: An effect that increased monotonically with the number of relevant comparisons would indicate a demanding comparison process, whereas a constant effect over all numbers of relevant items would indicate an automatic one. 


\section{Method}

Experiments 3-8 departed from the previous method in two major ways: First, array size was varied, so the visual stimuli differed as described below, and sccond, subjects were given no feedback regarding their performance (i.e., the memory-task feedback was omitted). Nevertheless, the memory task was still defined as primary, and the subjects were exhorted to do their best on it.

Apparatus and stimuli. In Experiments 3-8 the visual stimuli were arrays containing 4,8 , or 12 different letters equally spaced around an imaginary circle centered on the fixation point. Each array contained one target letter, an $A$ or a $V$. Each array size was represented by 48 different arrays in which each target letter appeared in each position equally often. As far as sampling limitations permitted, each nontarget letter (all remaining letters except $Q$ ) appeared in each posi-

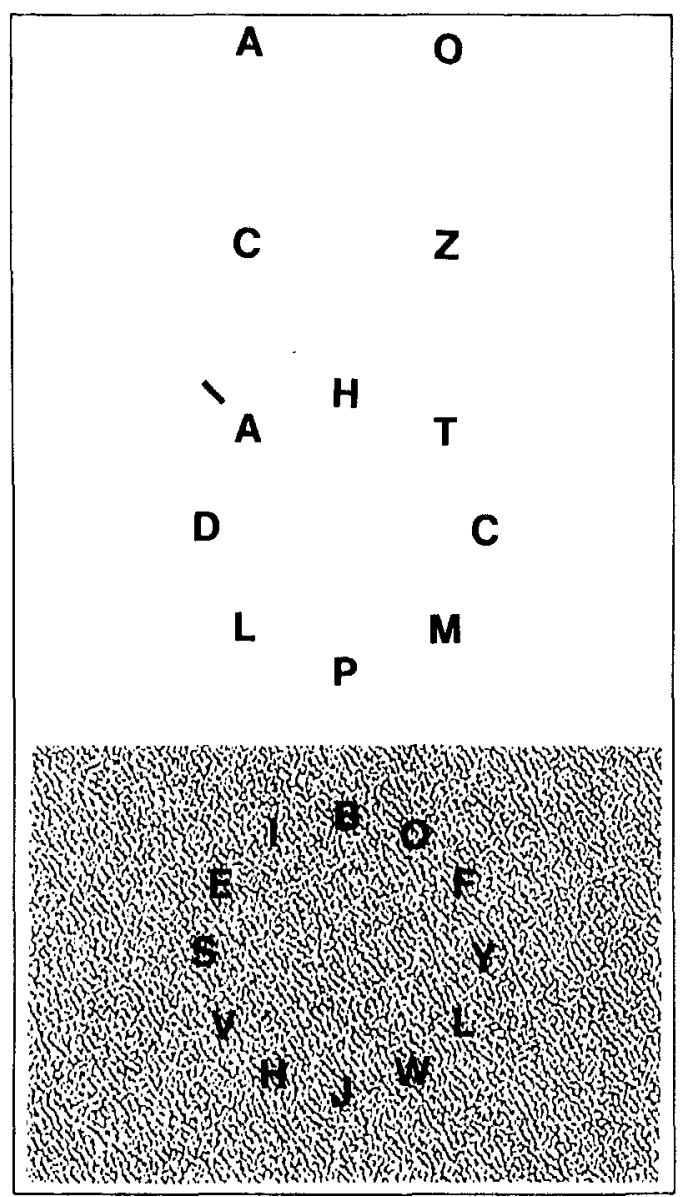

Figure 5. Examples of 4-, 8-, and 12-letter arrays with a bar marker (Experiment 3) on the 8-letter array and a noise mask (Experiment 5) on the 12-letter array. tion equally often. The arrays were made from black uppercase Letraset letters (\#727) mounted on white cards. Examples of each array size are shown in Figure 5.

Experiments 3, 5, 6, 7, and 8 used a Gerbrands three-field tachistoscope (Model T-3B-1) with a viewing distance of $80 \mathrm{~cm}$. At this distance, each letter subtended about $26^{\prime} \times 26^{\prime}$ of visual angle, and the diameter of the imaginary circle subtended $4^{\circ}$ of visual angle. A Scientific Prototype three-field tachistoscope (Model GB) was used in Experiment 4. Since its viewing distance was substantially longer, the stimuli appeared smaller: Each letter subtended about $19^{\prime} \times 19^{\prime}$ of vistal angle, and the diameter of the imaginary circle subtended about $2^{\circ} 53^{\prime}$ of visual angle.

In Experiment 3, a bar marker indicating the position of the target was presented on half of the trials. The bar was made from a capital $I$ (Letraset \#727), and it appeared as an extension of an imaginary radius outside the circle formed by the letters (see Figure 5). The bar subtended about $26^{\prime}$ in length and $5^{\prime}$ in width, and the separation between the bar and the target letter ( $A$ or $V$ ) was about $20^{\prime}$ of visual angle.

The bar markers were exposed for $100 \mathrm{msec}$ immediately before the arrays. To control for the alerting function of the bar marker (cf. Posner \& Boies, 1971), in the no-bar-marker conditions, a black dot was presented in the same interval prior to the arrays. It was made by filling in a capital $O$ (Letraset \#727), and it appeared superimposed on the fixation point.

Procedure. Experiment 3 differed from the general procedure in that the memory digits were read out loud by the experimenter, and recall was permitted as soon as the subject responded to the visual task.

\section{Results}

$V$ isual task. The mean reaction times in each combination of bar-marker, array-size, and memory-load conditions are displayed in Figure 6. Each point in the figure is based on 384 observations. Inspection of the figure makes it clear that reaction time increased with array size, $F(2,14)=50.28, p<.01$. However, the presence of a bar marker indicating the target's position reduced reaction time substantially, $F(1,7)=45.43, p<.01$, and diminished the effect of array size so that the interaction between them was significant, $F(2,14)=33.12, p<.01$. These effects replicate previous work (e.g., Holmgren, 1974a; Logan, Withey, \& Cowan, 1977) and serve to define comparison as a processing stage. 


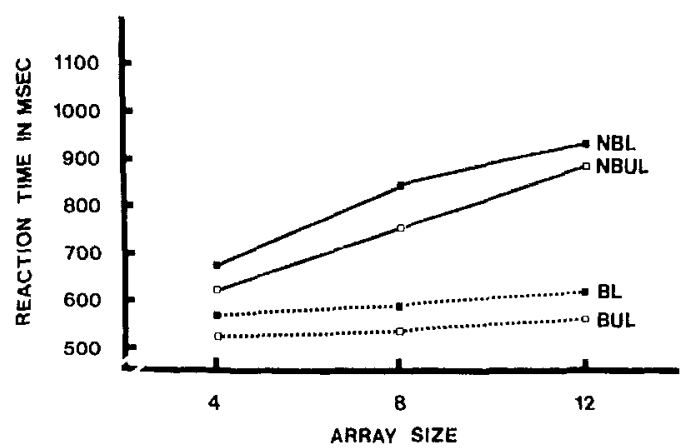

Figure 6. Mean reaction times in the visual task in Experiment 3 as a function of array size. (Barmarker and memory-load conditions are parameters: $B=$ bar marker ; $N B=$ no bar marker ; $L$ $=$ memory load; UL = no memory load.)

The requirement that subjects retain 7 digits during a visual trial increased reaction times overall by $59 \mathrm{msec}$, a difference that was highly significant, $F(1,7)=35.75, p<$ .01. However, there was one perturbation in this effect: Memory load increased reaction times to 8-Ietter arrays in the no-bar-marker condition by $95 \mathrm{msec}$, nearly twice the mean increase of $52 \mathrm{msec}$ for the other five comparisons (which ranged from 46 to 57 msec). This perturbation was large enough to produce significant interactions between memory load and array size, $F(2,14)=$ $4.98, p<.05$, and between memory-load and bar-narker conditions, $I f(1,7)=6.39, p<$ .05. The interpretation of these interactions is deferred to the Discussion section.

Reaction time decreased significantly over days, $F(3,31)=57.71, p<.01$, indicating a practice effect that interacted only with bar-marker conditions, $F(3,21)=7.11, p$ $<$.01. No-bar-marker conditions improved more than bar-marker conditions from Day 1 to Day 2, but at the same rate on subsequent days. The proportion of errors in each condition appears in Table 6 .

Memory task. The mean number of digits recalled in each combination of array-size and bar-marker conditions appears in Table 6. There were no significant effects in the analysis of variance performed on these data.

\section{Discussion}

Overall, the results support the hypothesis that comparisons between an array and a target set can be carried out without the involvement of attention. Concurrent memory load increased reaction time by a constant amount when 1 (the bar-marker conditions), 4 , or 12 items were relevant to the comparison process. Whereas the hypothesis that comparisons require attention predicted larger memory-load effects with more items relevant to comparison, the hypothesis that comparisons occur automatically predicted the obscrved invariance.

The weak interactions between memory load, bar-marker conditions, and array size should not be troublesome because the pattern of the interactions was not predicted by either hypothesis: The memory-load effect was constant for all except 8-letter, no-barmarker arrays, where it was larger. Nonmonotonic interactions such as these are not interpretable in the extended additive-factors method, so the preferred interpretation is that they were spurious. Indeed, they were not replicated in the remaining experiments (also see Logan, 1976).

The invariance of the menory-load effect bears on two current issues: First, theories of visual search are divided on the issue of attentional involvement in the comparison process; some argue for attentional involvement (e.g., Atkinson et al., 1969; Rumelhart, 1970; Schneider \& Shiffrin, 1977), and some argue against it (e.g., Estes, 1972, 1974; Gardner, 1973a, 1973b; Shiffrin \& Geisler, 1973). The invariant memory-load effect supports the argument against atten-

Table 6

Proportion of Errors in the Visual Task and Recall Accuracy (in parentheses) in the Memory Task (Across Subjects and Days) as a Function of Visual-Task Conditions in Experiment 3

\begin{tabular}{|c|c|c|c|}
\hline \multirow{2}{*}{$\begin{array}{l}\text { Bar } \\
\text { marker }\end{array}$} & \multicolumn{3}{|c|}{ Array size } \\
\hline & 4 & 8 & 12 \\
\hline \multicolumn{4}{|l|}{ Present } \\
\hline 0 digits & .04 & .04 & .06 \\
\hline 7 digits & $.08(6.12)$ & $.04(6.33)$ & $.06(6.15)$ \\
\hline \multicolumn{4}{|l|}{ Absent } \\
\hline 0 digits & .06 & .05 & .18 \\
\hline 7 digits & $.08(6.16)$ & $.09(6.04)$ & $.19(6.15)$ \\
\hline
\end{tabular}


tional involvement (also see Logan, 1976). Second, a number of recent studies have used cuing techniques like the present barmarker manipulation to assess attentional involvement. The effects of uncued items (or attributes) on performance have been offered as evidence of automatic processing, since attention is directed to the cued item (e.g., Butler, 1973, 1974; Dick, 1972; Keren, 1976; Mewhort, 1967; Willows, 1974; Willows \& MacKinnon, 1973; Neisser, Note 3 ). The invariant memory-load effect suggests that such cues may not direct attention. Most theories agree that directing attention both reduces the demands on attention and improves processing (e.g., Broadbent, 1958; Kahneman, 1973; Keele, 1973; Treisman, 1969). Experiment 3 has shown that the bar marker improved performance but did not reduce the demands on attention as measured by the memoryload effect (also see Gardner, 1973b).

\section{The Encoding Stage}

In the comparison stage, it is an internal representation of the array that is compared with a memorized target set. Thus, it is necessary to postulate the existence of mental operations prior to comparison whose function is to provide a suitable representatiton. This is the function that is identified with the term encoding.

Evidence that encoding is itself a processing stage, distinguishable from the comparison stage, comes from memory-search experiments. Sternberg (1967) and Johnsen and Briggs (1973) have shown that degrading an array by superimposing a visualnoise pattern (see Figure 5) increases reaction time by a constant amount, regardless of target-set size. Significantly, the presencc of noise has no (interactive) effect on the array-size function or the interaction between array size and target-set size (Johnsen \& Briggs, 1973). Precisely this additivity would be expected were encoding a separate processing stage whose duration is affected by stimulus quality.

\section{Experiment 4}

This experiment examined the automaticity of the encoding stage by varying stimulus quality, array size, and the extent of a concurrent memory load. Low-quality stimuli were produced by superimposing a noise mask on the arrays. These were compared with normal arrays, without a superimposed mask.

On the hypothesis that encoding requires attention, a larger memory-load effect was predicted for low-quality stimuli than for high-quality ones (i.e., a significant interaction between memory-load and masking conditions). On the hypothesis that encoding is automatic, constant memory-load effects were predicted for both high- and lowquality stimuli (i.e., no significant interaction between memory-load and masking conditions).

\section{Method}

The major methodological departure here was the presentation of a masking stimulus superimposed on the arrays on one half of the trials. The masking stimulus was a random-noise mask (Letratone LT134) mounted on clear Plexiglas and placed directly in front of the arrays to appear superimposed on top of them, filling the entire field (see Figure 5). The arrays were exposed for $1,500 \mathrm{msec}$ to ensure a high level of accuracy in the masking conditions, otherwise all methodological details were as described in the general method.

\section{Results}

$V$ isual task. The mean reaction times for each combination of masking, array-size, and memory-load conditions are displayed in Figure 7. Each point in the figure is based on 384 observations. Again, reaction time increased with array size, $F(2,14)=63.88$, $p<.01$, and memory load, $F(1,7)=32.26$, $p<, 01$, but their effects were clearly additive; the interaction between them was nonsignificant, $F(2,14)<1$. This supports the conclusion drawn from Experiment 3 that the comparison process in visual search is automatic.

The presence of a superimposed noise mask increased reaction time overall by 68 msec, $F(1,7)=16.71, p<.01$. In the presence of this substantial main effect, the nonsignificance of the Masking $\times$ Array Size interaction, $F(2,14)<1$, suggests that en- 


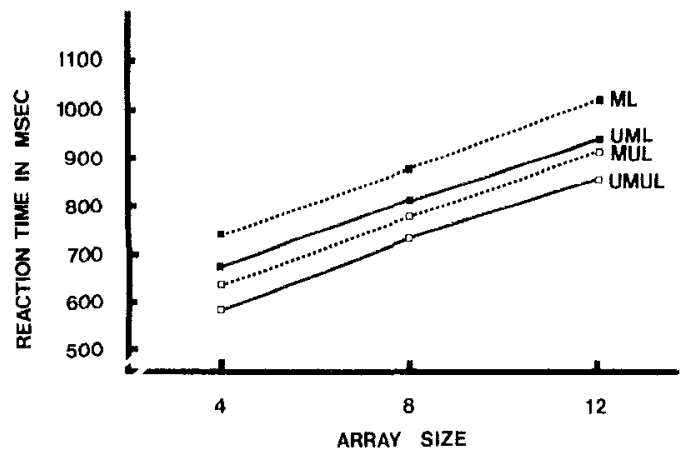

Figure 7. Mean reaction times in the visual task in Experiment 4 as a function of array size. (Masking and memory-load conditions are parameters: $M=$ mask; $U M=$ no mask; $L=$ memory load; UL = no memory load.)

coding and comparison may be treated as separate processing stages. The nonsignificance of the Masking $\times$ Memory Load interaction, $F(1,7)<1$, suggests further that the encoding stage functions without the involvement of central processing capacity.

As in Experiment 3, reaction time decreased over days, $F(3,21)=27.97, p<$ .01 . The interaction between array size and days was significant, $F(6,42)=2.81, p<$ .05 , indicating a small but stable reduction in the array-size effect over days. The proportion of errors in each experimental condition appears in Table 7.

Memory task. The mean number of digits recalled in each combination of array-size and masking conditions appears in Table 7 . The only significant effect in the analysis of the memory data was that of days, $F(3,21)$ $=20.15, p<.01$, indicating a gradual improvement in memory performance with practice. The nonsignificance of all main effects and interactions involving parameters of the visual task indicates that a constant amount of attention was allocated to the visual task in all memory-load conditions.

\section{Discussion}

The mutual additivity of the effects of array size, masking conditions, and memory load suggests that encoding and comparison involve separate processing stages, each of which functions automatically. The additivity of the effects of array size and memory load found here corroborates the interpretation of Experiment 3, namely, that the interactions involving array size and memory load were spurious.

The conclusions regarding the automaticity of the encoding stage must be qualified somewhat. Encoding has been construed as preparing a suitable representation for comparison. Clearly, what is suitable depends on the nature of the target set. Tasks that require translation of the array to the form of the target set may well involve different mental operations than those required here (c.g., Clifton, Cruse, \& Gutschera, 1973), and such operations may require attention. Indeed, complementary translations on the target set would appear to demand attention (Millar, 1975; Posner \& Klein, 1973).

Thus the nature of the task may be an important determinant of the capacity demands of component stages inasmuch as task demands determine the construction of each stage. The demands of encoding, then, depend on the task. For simple search tasks (i.e., the present experiments), however, encoding appears to be automatic.

\section{The Decision Stage}

Once the encoded array has been compared with the target set, the evidence accumulated in the comparison stage must be assigned to one of two equivalence classes defined by instructions (i.e., $A$ versus $V$ ). The decision stage is most often studied in

Table 7

Proportion of Errors in the Visual Task and Recall Accuracy (in parentheses) in the Memory Task (Across Subjects and Days) as a Function of Visual-Task Conditions in Experiment 4

\begin{tabular}{|c|c|c|c|}
\hline \multirow{2}{*}{$\begin{array}{l}\text { Masking } \\
\text { condition }\end{array}$} & \multicolumn{3}{|c|}{ Array size } \\
\hline & 4 & 8 & 12 \\
\hline \multicolumn{4}{|l|}{ Mask } \\
\hline 0 digits & .02 & .07 & .13 \\
\hline 7 digits & $.04(5.98)$ & $.08(6.16)$ & $.17(6.95)$ \\
\hline \multicolumn{4}{|l|}{ No mask } \\
\hline 0 digits & .03 & .04 & .08 \\
\hline 7 digits & $.03(6.14)$ & $.04(6.08)$ & $.10(6.16)$ \\
\hline
\end{tabular}


the yes-no version of character-classification tasks by comparing reaction times associated with the different decision outcomes (i.e., yes and no). In general, no decisions take longer than yes decisions, and the difference is consistent across array size or target-set size (Nickerson, 1972; Sternberg, 1975), suggesting that comparison and decision involve separate stages.

\section{Experiment 5}

Array size, decision outcome, and menory load were varied factorially to examine the automaticity of comparison and decision stages. On the hypothesis that the decision stage requires attention, it was predicted that memory load and decision outcome would interact. On the hypothesis that the decision stage functions automatically, additive effects were predicted.

\section{Method}

The major departure in this experiment was procedural: Subjects were instructed to respond yes if an array contained an $A$, and to respond no otherwise. Although the letter $V$ was present on all arrays receiving no responses, subjects apparently did not take it into account in responding. After the experiment, subjects were asked how they decided there was an $A$ present, and none indicated knowledge of the (negative) correlation between $A$ and $V$. When the correlation was subsequently described, 2 of 16 subjects reported noticing a preponderance of $V$ s, and one reported noticing the correlation. No subject reported searching for a $V$ to decide upon a no response.

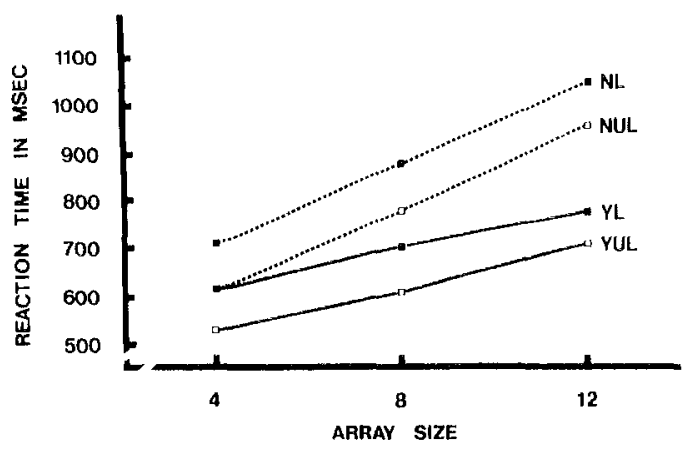

Figure 8. Mean reaction times in the vistual task in Experiment 5 as a function of array size. (Decision-type and memory-load conditions are parameters: $\mathrm{Y}=$ yes; $\mathrm{N}=$ No; $\mathrm{L}=$ memory load ; $\mathrm{UL}=$ no memory load.)
Table 8

Proportion of Errors in the Visual Task and Recall Accuracy (in parentheses) in the Memory Task (Across Subjects) as a Function of Visual-Task Conditions in Experiment 5

\begin{tabular}{|c|c|c|c|}
\hline \multirow{2}{*}{$\begin{array}{l}\text { Decision } \\
\text { type }\end{array}$} & \multicolumn{3}{|c|}{ Array size } \\
\hline & 4 & 8 & 12 \\
\hline \multicolumn{4}{|l|}{ Yes } \\
\hline 0 digits & .05 & .07 & .17 \\
\hline 7 digits & $.09(5.38)$ & $.07(5.13)$ & $.17(4.96)$ \\
\hline \multicolumn{4}{|l|}{ No } \\
\hline 0 digits & .02 & .03 & .08 \\
\hline 7 digits & $.02(5.24)$ & $.02(4.92)$ & $.15(5.25)$ \\
\hline
\end{tabular}

Note that each subject served in only one session (see Table 1).

Decision outcome (yes-no) and array size varied randomly within blocks. The basic four-block procedure was retained, and memory-load conditions were run in alternating blocks. Half of the subjects began with a memory-load block, and half began with a no-memory-load block.

\section{Results}

$V$ isual task. The mean reaction times for each decision-outcome, array-size, and memory-load condition are displayed in Figure 8. Each point in the figure is based on $192 \mathrm{ob-}$ servations. Once again, reaction time increased significantly with array size, $F(2$, $30)=129.08, p<.01$, and with niemory load, $F(1,15)=27.91, p<.01$, and once again, the interaction between them was not significant, $F(2,30)<1$. These findings corroborate Experiments 3 and 4 but should be interpreted with caution because of anomalous results in the memory task.

Characteristic of the yes-no task, reaction times were significantly longer for no decisions than for yes decisions, $F(1,15)=$ $74.16, p<.01$. The slope of the no function was larger than the slope of the yes function, so much so that the interaction between decision outcome and array size was highly significant, $F(2,30)=24.98, p<.01$.

The requirement that subjects retain 7 digits in memory increased yes reaction times by $86 \mathrm{msec}$ and no reaction times by 95 msec. The interaction between memory load and decision outcome was not significant, $F(1,15)<1$, providing some sup- 
port for the hypothesis that the decision stage functions automatically. The proportion of errors in each condition is presented in Table 8.

Memory task. The mean number of digits recalled in each combination of array size and decision outcome appears in Table 8. While the effect of decision outcome was not significant, $F(1,15)<1$, both the main effect of array size and the interaction of array size with decision outcome were significant, $F(2,30)=8.78$ and 3.78 , respectively, $p<.05$. A closer inspection of the data reveals a monotonic reduction in recall accuracy as array size increased for yes decisions, and a more complex pattern for no decisions: Recall accuracy was high with 4and 12-letter arrays but low with 8-letter arrays.

\section{Discussion}

The reaction time data, considered by themselves, are relatively clear: Memory load did not interact with array size or decision type, although all three variables produced substantial main effects. The invariance of the memory-load effect suggests that each condition demancled the same amount of attention. The independence of attention demands and processing time, in turn, suggests that the stages defined by these parameters function automatically. Moreover, the additivity of memory-load and decisionoutcome effects replicates the additivity found in Experiments 1 and 2 with memory search.

The memory data, however, are not so clear. The dependence of memory performance on array size and decision outcome (jointly) suggests a trade-off between tasks such that some visual conditions received more attention than others. The pattern of the interaction, however, is difficult to interpret in terms of a systematic trade-off strategy that is sensitive to visual-task conditions, so it is possible that the effects were spurious. Indeed, array size did not affect memory performance in any other experiment (especially Experiment 8), nor did decision outcome in memory-search experiments.

The interaction between array size and decision outcome is noteworthy, since their effects are typically additive (e.g., Atkinson et al, 1969; Holmgren, 1974a). Additivity is often interpreted as indicating that all items are compared before a decision is made, that is, search is exhaustive, while steeper slopes for no than for yes decisions often suggest that the comparison process stops once sufficient evidence for a decision has accumulated, that is, search is self-terminating (see Sternberg, 1969a, 1975). The difference between the present results and earlier findings (Atkinson et al., 1969; Holmgren, 1974a) might reflect a difference in strategy: The earlier studies used smaller arrays ( $1-5$ items) which would not benefit much from a self-terminating strategy. Assuming a search rate of $20 \mathrm{msec}$ per item, the maximum benefit would be 80 nisec. By contrast, the naximum benefit with the large arrays of the present study would be 220 msec. Thus, experiments involving small arrays may induce an exhaustive strategy, while large-array studies may induce a selfterminating strategy. Indeed, with arrays as large as those studied by Neisser and his colleagues (50 lines of 6 items), efficient search is necessarily self-terminating (e.g., Neisser, 1963; Neisser et al., 1963).

The evidence for self-terminating search is inconsistent with Holmgren's (1974b) claim that yes-no search is characteristically exhaustive and involves different operations than forced-choice search because forcedchoice search is self-terminating. There is nothing in the present data to suggest that yes-no and forced-choice search involve substantially different operations.

\section{The Response Selection Stage}

The fourth stage in the classification task is the response-selection stage. At this stage, the subject has already classified the stimulus in terms of instructed equivalence classes and need only execute an appropriate response. The response is thought to be selected from a response set by the application of situation-specific rules for mapping equivalence classes onto the response set.

In Experiments 6 and 7 the responseselection stage was identified with the effects 
of variations in the compatibility of stimulus-response (S-R) relations (Deininger \& Fitts, 1955; Kecle, 1973; Welford, 1968). The S-R compatibility manipulation was attractive becatrse it harl been associated with the response-selection stage, using the ardlitive-factors method (Biederman \& Kap)lan, 1970); Rabbitt, 1967), and because it has been implicated as a determinant of the attention demands of tasks in concurrentlask situations (Broadbent \& Gregory, 1965; Crowder, 1967; Keele, 1967). Txperiment 6 examined the compatibility of relations between one stimulus set and one response set, while Experiment 7 compared the compatibility of two response sets with one stimulus set.

\section{Experiment 6}

This experiment used vocal responses. In the compatible condition (high S-R compatibility), subjects spoke the name of the target letter jresent in the array. The incompatible condition (low $\mathrm{S}-\mathrm{R}$ compatibility) was produced by simply reversing the S-R mapping. Whereas " $A$ " was the correct response to an $A$ in the array in the conpatible condition, "V" became the correct response in the incompatible conclition. The advantage of this arrangement was that stimulus conclitions, response uncertainty, and the responses thenselves remained unchanged as $S-R$ compatibility was varied.

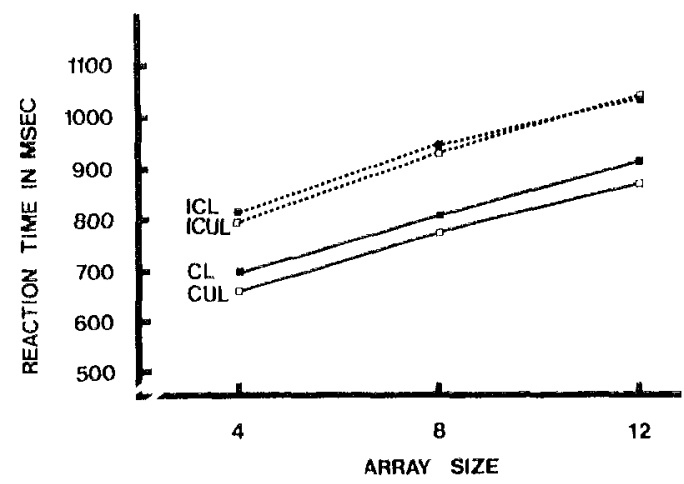

Figure 9. Mean reaction times in the visual task in Experiment 6 as a function of array size. (Stimulus-response compatibility and memory-load conditions are parameters: $C=$ compatible; $I C=$ incompatible; $\mathrm{I}=$ memory load; $\mathrm{UI}_{-}=$no memory load.)
Only the S-R mapping changed (c.f. Alluisi, Strain, \& Thurmond, 1964; Broadbent \& Grogory, 1962; Hawkins, MacKay, Holley, Friedin, \& Cohen, 1973, Experiment 1).

On the hypothesis that response selection requires attention, it was predicted that the difference between the $S-R$ compatibility conditions would increase when the task was performed with a concurrent memory load (i.e., a significant interaction between memory-load and S-R compatibility conditions). On the hypothesis that response selection does not require attention, it was predicted that the difference between the S-R compatibility conditions would not change as memory load was manipulated (i.e., no significant interaction between memory load and $S-R$ compatibility).

\section{Method}

This experiment differed from the previous ones in that vocal responses were used. Again, the twoalternative ( $A$ or $V$ ) forced-choice procedure was used.

\section{Results}

Visual task. The mean reaction times for cach combination of array-size, memoryload, and S-R compatibility conditions are displayed in Figure 9. Each point in the figure is based on 384 observations. Reaction tinc increased significantly with array size, $f(2,14)=101.24, p<.01$, and was longer with incompatible $\mathrm{S}-\mathrm{R}$ relations, $F(1,7)=$ $79.18, p<.01$. The contention that array size and S-R compatibility affect different stages was supported by the nonsignificance of the interaction between them, $F(2,14)$ $=2.34, p>05$, and the nonsignificance of all higher order interactions involving both of them.

Unlike the previous experiments, the memory-load effect was small (26 $\mathrm{msec}$ ) and failed to reach significance, $F(1,7)=$ $3.74, .05<p<.10$. However, the interaction of memory load and days was significant, $F(3,21)=3.58, p<.05$, indicating a substantial (74 misec) memory-load effect on the first day, but a negligible effect (10 msec) on all subsequent days. While reaction times in all conditions decreased signifi- 
cantly over days, $\Gamma(3,21)=9.80, p<.01$, the reduction was greatest in conditions involving a memory load.

In this experiment, as in the previous experiments, the simple interaction between memory load and array size failed to reach significance, $F(2,14)<1$; however, the three-way interaction between array size, memory load, and days was significant, $F(6$, $42)=3.54, p<.01$. It reflects a smaller memory-load effect for larger arrays on the first day, whereas the memory-load effect was consistent (and small) across array size on subsequent days. This pattern of differences would not be predicted on the hypothesis that the comparison stage requires attention, and it need not concern us further.

The interaction between memory load and S-R conpatibility was also nonsignificant, $F(1,7)=3.45, p>05$. If anything, there was a tendency for the memory-load effect to be smaller in the incompatible condition on the first clay, clearly contradicting the prediction that the attention demands of a task are greater the lower the degree of S-R compatibility (c.f. Broadbent \& Gregory, 1965; Crowder, 1967, Keele, 1967). Of course, the present experinjent exploited only one type of S-R compatibility (Deininger \& Fitts, 1955). The proportion of errors in each condition (across subjects and days) is presented in Table 9.

Menuory task. Table 9 contains the mean number of digits recalled for each combination of array-size and S-R compatibility conditions. In the analysis, only the effect of days was significant, $F(3,21)=17.23$. Memory performance improved over days by the same amount in each condition. Thus there is no evidence here suggesting a tradeoff between recall accuracy and reaction time.

\section{Discussion}

The contention that S-R compatibility affects a response-selection stage separate from the comparison stage was supported by the additivity of the effects of array size and $S-R$ compatibility. In this context, the additivity found between memory load and S-R compatibility becomes meaningful : In-
Table 9

Proportion of Errors in the Visual Task and Recall Accuracy (in parentheses) in the Memory Task (Across Subjects and Days) as a Function of Visual-Task Conditions in Experiment 6

\begin{tabular}{cccc}
\hline $\begin{array}{c}\text { Stimulus- } \\
\text { response } \\
\text { compatibility }\end{array}$ & \multicolumn{3}{c}{ Array sizc } \\
\cline { 2 - 4 } & \multicolumn{2}{c}{8} & \multicolumn{1}{c}{12} \\
\hline $\begin{array}{c}\text { Compatible } \\
0 \text { digits }\end{array}$ & .02 & .06 & .16 \\
7 digits & $.01(5.95)$ & $.03(5.89)$ & $.15(5.94)$ \\
$\begin{array}{c}\text { Incompatible } \\
0 \text { digits }\end{array}$ & .03 & .08 & .17 \\
7 digits & $.01(5.80)$ & $.06(5.88)$ & $.13(5.98)$ \\
\hline
\end{tabular}

compatible $\mathrm{S}-\mathrm{R}$ relations may increase the time required for response selection without affecting the attention it demands. This conclusion is further supported by the finding that the compatibility effect remained constant over days while the memory-load effect (the index of attention demands) diminished.

\section{Experiment 7}

This experiment compared the attention demands of vocal and manual responses. Subjects either spoke the name of the target letter presented $(A$ or $V$ ) or pressed the appropriate button. A significant interaction between memory load and response type would indicate differential attention clemands, while additivity would indicate equivalent attention demands.

\section{Method}

This experiment differed from the previous ones in that two response buttons as well as a voiceactivated relay were connected to a millisecond timer so that it would be stopped by vocal or manual responses. Vocal- and manual-response conditions were run in separate blocks in the manner described in the General Method. Again, the two-alternative ( $A$ or $V$ ) forced-choice procedure was used.

\section{Results}

Visual task. Mean reaction times for each combination of array-size, memoryload, and response-type conditions are dis- 


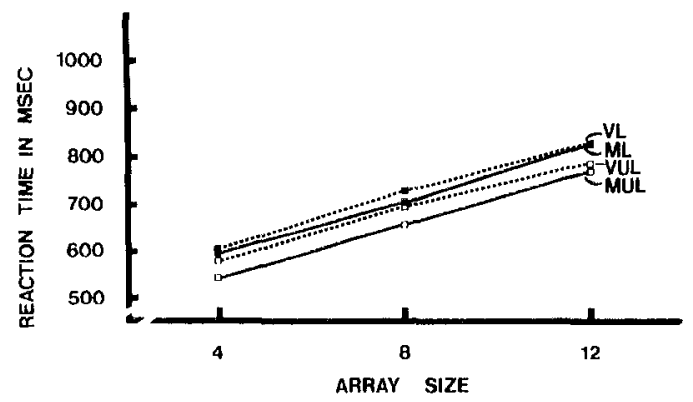

Figure 10. Mean reaction times in the visual task of Experiment 7 as a function of array size. (Response-type and memory-load conditions are parameters: $V=$ vocal; $M=$ manual $; I_{1}=$ memory load; UL = no memory load.)

played in Figure 10. Each point in the figure is based on 384 observations. Once again, reaction time increased with array size, $F(2$, $14)=38.58, p<.01$, and with memory load, $F(1,7)=21.18, p<.01$, and once again, the interaction between array size and memory load was not significant, $F(2,14)<1$, further supporting the possible automaticity of the comparison stage.

Overall, vocal reaction times were 25 msec longer than manual reaction times, but the difference was not significant, $F(1,7)$ $=2.52, p>05$, nor were the interactions between response type and memory load, $F(1,7)<1$, and response type and array size, $F(2,14)<1$. Reaction time decreased over rlays, $F(3,21)=36.40, p<.01$, and the array-size effect diminished with practice, $F(6,42)=7.19, p<.01$. The proportion of errors in each combination (across subjects and days) is displayed in Table 10.

Memory task. The mean number of digits recalled in each combination of array-size and response-type conditions appears in Table 10 . Once again, only the effect of days was significant in the analysis, $F(3,21)=$ $18.90, p<.01$.

\section{Discussion}

This experiment provides no evidence that vocal and manual responses differ in the demands they place on attention, which, together with the results of Experiment 6, suggests that the response-selection stage functions automatically. Thus, it appears that no stage in visual search requires attention. The consistent main effect of memory load suggests that the task demands attention, but the demands canot be localized in any stage. This surprising conclusion will be discussed presently; but now let us consider a final investigation of memory-load effects.

\section{Experiment 8}

It is significant that none of the parameters of the visual task had reliable effects on memory performance. This is further evidence that none of the stages associated with the parameters take attention. However, the high level of recall accuracy over all experiments $(84 \%)$ is problematic in that ceiling effects may have masked true differences in memory performance. Experiment 8 was run as a parametric variation of memory load and array size designed to produce data free of ceiling effects so that any hidden influence of visual-task parameters could emerge.

\section{Method}

The experimental conditions were the factorial combinations of three levels of array size $(4,8$, or 12 letters) and four levels of memory load ( $0,4,8$, or 12 words). The experiment was run as a singlesession 144-trial experiment divided into four blocks of 36 trials. Array size varied randomly within blocks, and memory load varied between

Table 10

Proportion of Errors in the Visual Task and Recall Accuracy (in parentheses) in the Memory Task (Across Subjects and Days) as a Function of Visual-Task Conditions in Experiment 7

\begin{tabular}{clll}
\hline & \multicolumn{3}{c}{ Array size } \\
\cline { 2 - 4 } $\begin{array}{c}\text { Response } \\
\text { type }\end{array}$ & \multicolumn{1}{c}{4} & \multicolumn{1}{c}{8} & \multicolumn{1}{c}{12} \\
\hline Vocal & & & \\
0 digits & .08 & .10 & .18 \\
7 digits & $.09(6.07)$ & $.06(6.09)$ & $.15(6.09)$ \\
Manual & & & \\
0 digits & .01 & .03 & .14 \\
7 digits & $.00(5.78)$ & $.03(5.85)$ & $.13(5.91)$ \\
\hline
\end{tabular}


blocks in four orders derived from a balanced $4 \times 4$ Latin square (see General Method).

The memory stimuli were drawn from the Toronto word pool, a pool of 1,056 two-syllable words from the AA and $A$ categories of the Thorndike-Lorge (1944) word-frequency count. Lists of 4,8 , and 12 words were recorded at an approximate rate of $1.24 \mathrm{sec}$ per word, preceded by a warning signal and followed by a ready signal about $2.5 \mathrm{sec}$ after the last word. The retention interval was about $8.5 \mathrm{sec}$.

\section{Results and Discussion}

Visual task. Mean reaction times for each combination of array-size and memory-load conditions are displayed in Figure 11. Each point in the figure is based on 192 observations. The effects of both array size and memory load were significant, $F(2,30)=$ 123.74 , and $F(3,45)=5.74$, respectively, $p<.01$, but the interaction between them was not, $F(6,90)<1$. This replicates the previous findings of additivity under more severe loads. Notice that reaction time increased monotonically with memory load for loads of 0,4 , and 8 words but was slightly (not significantly) reduced for loads of 12 words. The monotonic increase replicates the results of Shulman and his collcagues (Shulman \& Greenberg, 1971; Sht1man et al., 1971), but the reduction with 12-word loads does not. However, Shulman's experiments used a maximum load of 10 items, and it is possible that the effect reaches asymptote between 8 and 12 items.

Memory task. The mean numbers of

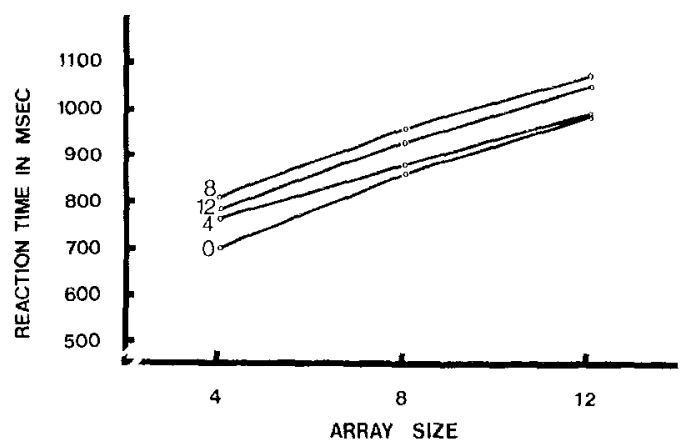

Figure 11. Mean reaction times in the visual task of Experiment 8 as a function of array size. (The number of words concurrently in memory is the parameter.)
Table 11

Proportion of Errors in the Visual Task and Recall Accuracy (in parentheses) in the Memory Task (Across Subjects) as a Function of Visual-Task Conditions in IExperiment 8

\begin{tabular}{rlll}
\hline & \multicolumn{3}{c}{ Array size } \\
\cline { 2 - 4 } $\begin{array}{c}\text { Memory } \\
\text { load }\end{array}$ & \multicolumn{4}{c}{8} & \multicolumn{1}{c}{8} & 12 \\
\hline 0 words & .01 & .07 & .22 \\
4 words & $.00(3.80)$ & $.09(3.75)$ & $.23(3.75)$ \\
8 words & $.02(4.60)$ & $.08(4.63)$ & $.22(4.47)$ \\
12 words & $.00(4.89)$ & $.12(4.84)$ & $.20(4.74)$ \\
\hline
\end{tabular}

words recalled in each array-size and memory-load condition appear in Table 11. Since few subjects recalled more than one word in correct order, the order requirements were relaxed and a word was scored correct if it appeared in any position in the list.

The number of words recalled increased with the number presenterl, $F(2,30)=$ $43.72, p<.01$, but was unaffected by array size. Neither the main effect of array size, $F(2,30)=1.67$, nor the interaction of array size with memory load, $F(4,60)<1$, approached significance. Notice that the lack of array-size effects with loads of 8 and 12 words cannot be attributed to ceiling effects, as the number of words recalled in each of these conditions was considerably less than the number presented.

A final point of interest is that significantly more words were recalled from 12 word lists than from 8-word lists, $t(30)$ $=3.17, p<.01$, yet 12 -word lists had a slightly smaller effect on reaction time. The increase in recall, however, was small (.25 words) and might not be expected to influence reaction time, especially near the asymptote of the memory-load effect.

\section{General Discussion}

Most theories of attention would predict that a concurrent primary task will increase visual reaction time by an amount proportional to the attention demands of the visual task. Sternberg's (1969a, 19691) additivefactors method was used in an attempt to associate observable attention demands with 
particular processing stages. The amount of interaction between concurrent task difficulty (memory load) and parameters known to influence a particular processing stage was a measure of the attention demands of that stage. The method was shown to be both internally consistent and consistent with another method that assesses attentional involvement. It was then applied to the analysis of four stages sufficient to perform a visualsearch task.

Memory load did not interact with parameters associated with encoding, decision, and response-selection stages, and of three parameters associated with the comparison stage (array size, presence or absence of a bar marker, and target-set size), only targetset size interacted significantly with memory load. Thus it appears that a great deal of processing in classification tasks is automatic. ${ }^{2}$ The implications of this conclusion are discussed in the next four sections.

\section{Structural and Capacity Models of Attention}

Structural models of attention consist of a limited-capacity channel, a filter to protect the channel from overload, and preliminary processes to provide the informational basis for selection. Since the preliminary processes and the filter are outside the channel, they are not subject to capacity limitations. Since they precede the channel in the information flow, a clear pattern of attentional involvement across processing stages may be predicted: Early stages will not demand attention, but stages closer to the effectors will.

The point of transition represents the boundary of the limited-capacity channel, and all subsequent stages should require attention, as they are inside the channel. ${ }^{3}$ Thus, structural models predict a step function of attentional involvement across stages.

Capacity models, on the other hand, make no predictions about the locus of attentional involvement, as attention is an energistic property apart from structure. Any pattern of attentional involvement across stages is consistent with capacity models.

The results of the present experiments are inconsistent with structural models. The visual-search experiments (Experiments 38) examined four stages sufficient to perform the task and found no evidence of attentional involvement in any of them. The memorysearch experiments (Experiments 1 and 2) showed some evidence of attentional involvement in the comparison stage, but none in the subsequent decision stage. Thus the observed pattern of attentional involvement across stages was not the step function predicted by structural models. Of course, the observed pattern is consistent with capacity models.

If we accept that the same comparison stage is involved in visual search and memory search, the experiments have demonstrated that all parameters that affect a stage do not contribute equally to its attention demands. The demands of comparison depend on target-set size but not array size or barmarker conditions (also see Howard, 1975, and Logan, 1976). Furthermore, since the range of parameters that might affect the stages studied was not sampled exhaustively, it is possible that some new parameter $(\mathrm{s})$ may show evidence of attention demands in one (or more) of the stages. The demands of response selection, for example, may depend on the number of possible responses, but not on the compatibility of various S-R arrangements. A more conservative conclusion, then, is that some aspects of all processing stages are automatic.

This challenges the structural view of a unified stage of attentive analysis in that all components of a stage need not contribute to its attention demands. By contrast, capacity models are comfortable with this sug-

\footnotetext{
a Howard Egeth (1977) lass also found evidence for automatic encoding, discrimination, and response selection in choice reaction time using a memory-load procedure.

3 The boundary of the limited-capacity channel has not yet been established unequivocally. Some believe it occurs after processing of physical leatures (e.g., Broadbent, 1958), and others believe it occurs after semantic analysis (c.g., Deutsch \& Deutsch, 1963). For the present purposes, the locus is not as important as the transition itself, since a sharp transition in attention demands is evidence supporting structural models. The locus matters only if structural models provide the best description of the data.
} 
gestion. Attention refers to the activation of structural units though the units themselves may not be defined. The subsequent discussion suggests steps toward definition.

\section{What Takes Attention?}

It was clear throughout the experiments that the visual task required attention-the main effect of memory load was quite reliable-yet there was no clear evidence that attention was involved in the execution of any stage's function. The components of the task seem automatic, but the task itself is not. Perhaps the stage structure of a task should be viewed as a temporary assembly of automatic, special-purpose processors organized by attention to deal with the task at hand. This is not unreasonable, given the rather arbitrary nature of the sequence of stages we have studied. It may take attention, then, to prepare an appropriate sequence of structures and maintain it until a stimulus has appeared.

There is currently a great deal of sympathy for this notion among attention theorists (e.g., LaBerge, 1973a, 1973b; Posner \& Boies, 1971; Posner \& Snyder, 1975a, 1975b; Thomas, 1974), for the empirical properties of preparation suggest an attentional process. Preparation improves reaction time in that prepared reactions are faster than unprepared ones (Beller, 1971; Bertelson, 1967; Posner \& Boies, 1971), but the improvement with preparation is limited to a narrow range of stimuli and is bought at the cost of less efficient processing for stimuli outside this range (Gottsdanker, 1975; LaBerge, 1973a ; Posner \& Snyder, 1975b; Rosch, 1975; Rosch, Simpson, \& Miller, 1976).

Clear evidence for the involvement of attention in maintaining preparation is available in Comstock's (1975) doctoral thesis. Her subjects performed a primary lettermatching task in which a warning signal and two letters to be matched were presented in succession. The momentary attention demands of the letter-matching task were assessed from reaction times to an auditory probe presented at various times throughout the time course of the visual task. As is typically found in these studies, probe reaction times were uniform throughout the warning interval and the presentation of the first letter but rose substantially around the presentation of the second letter, presumably reflecting the greater attention demands of response-related processes (Comstock, 1973; Millar, 1975; Posner \& Boies, 1971 ; Posner \& Klein, 1973). When the probe task was run as a single-task control (i.e., the visual events were the same but subjects ignored them and responded only to the probes), reaction times were uniform throughout the warning interval and the presentation of both letters. Interestingly, single-task probe reaction times were consistently faster than their dual-task counterparts, even during the intertrial interval, when the visual task could not have demanded attention for execution. Becker (1976) found a similar elevation of reaction time when subjects expected a second task but did not have to perform it.

The memory-load effects in the present experiments may be explained in terms of preparation. The primary (memory) task may have required so much attention that the amount remaining was not sufficient to optimally prepare the secondary (visual) task, and consequently reaction times increased. ${ }^{4}$ Target-set size was the only parameter to interact with memory load because it was the only one to vary the amount of preparation necessary to perform the task (i.e., 1, 2, or 4 targets). Indeed, the memorysearch experiments were conducted after the visual-search studies to test the hypothesis that attention demands depend on the amount to be prepared not on the amount to be processed.

Capacity models provide a theoretical link between attention and preparation. Preparation may result from allocating capacity

4 An interesting implication of Comstock's (1975) findings is that subjects need not have executed demanding operations in the memory task during the reaction time interval for reaction time to increase; preparing to execute the ojerations may have been sufficient. Note that this excludes any interpretation based on switching attention from the memory task to the visual task. 
to activate task-relevant structures before the stimulus appears. Stimulus presentation will then provide a pattern of activation that when combined with the preparatory attentional activation will determine an appropriate response. Attentional activation may organize a sequence of structures to form a "path of least resistance" which momentarily dominates habitual response tendencics. This principle is developed in greater detail in the next section.

\section{Comparison Stage Revisited}

$A$ model of the comparison stage must account for the seemingly demanding nature of memory search and the automatic nature of visual search found in the present experiments. Similar findings have been reported when subjects change the instructed S-R mapping in response to a signal in the array while engaged in search: Changing the S-R mapping increases the slope of the targetset-size function (Howard, 1975) but not the array-size function (Logan, 1976). The principle of preparation may be developed to provide an appropriate model.

The structure underlying the comparison stage might involve units, for example, sets of feature detectors, capable of representing items from the visual array and the target set by characteristic patterns of activation. The activation of the array items is presumably an automatic consequence of stimulus presentation; indeed, this is what the present studies stuggest (particularly Experiment 4). By contrast, target-set items require an internal source of activation, since the target set is usually presented long before the array. Central processing capacity is a likely candidate here, particularly in view of the results of Experiments 1 and 2 (also see Baddeley \& Ecob, 1973; Corballis, 1975).

The comparison process might involve the integration of the two sources of activation in the structure once the array is presented so that units representing items common to the array and the target set will be activated more than the other nonmatching items from either set. The additional activation is thus a signal to be detected in the presence of noise from the activation of nonmatching items, and a response can be emitted once the signal-to-noise ratio exceeds a threshold. If the integration process is extended in time, the time to reach threshold (and thus reaction time) will be longer the lower the signal-to-noise ratio (see Anderson, 1973, for a formal development, and Estes, 1972, 1975a, 1975b, for similar views). Such a process can produce both the separate and the joint effects of array size and target-set size reviewed earlier.

The consistent additivity of memory load and array size in the present studies suggests that integration is an automatic process, initiated by stimulus presentation (also see Togan, 1976). The interaction of memory load and target-set size, then, reflects the use of attention in preparing the target set. If memory load reduced the preparatory activation of the target set, lower signal-tonoise ratios would result. The effect would be greater with larger target sets, thus the interactions. Alternatively, the target-set items may be optimally activated under all conditions so that their demands produce deficits in other parts of the structure. This, too, would yield appropriate interactions. The automatizing of memory search with specific practice seen in Experiment 1 presumably reflects the automatizing of preparatory processing. Perhaps with sufficient practice, the target set may be prepared as a unit so attention demands are equal for all set sizes.

However, this explanation is by no means unique. Most of the effects could be accounted for by a model that assumes two separate serial comparison processes, one for the array and one for the target set (Townsend \& Roos, 1973). Indeed, the interaction of concurrent activity with target-set size (also see Howard, 1975, and Sternberg, 1969b, Experiment 5) but not with array size (also see J.ogan, 1976) supports the notion of separate processes. Alternatively, Schneider and Shiffrin's (1977) singleprocess model can explain most of the results except the different memory-load effects in visual search and memory search. In their model, both visual search and mem- 
ory search are under attentional control as long as their respective slopes are greater than zero, and both should show interactions with memory load. Of course, the model could be changed to accommodate the present findings.

Ultimately, the choice between these models and the preparation model is a matter of parsimony and aesthetics. The serial, self-terminating comparison process central to both dual- and single-process models would require considerable attentional control during the execution of comparisons. In view of the present evidence for widespread automaticity in classification tasks, this is not a desirable feature. By contrast, the preparation model performs the same function without the attendant complexity. Only two components require attentional control, the activation of the target set and, possibly, the threshold setting. Once these are prepared, the comparison process will run off attomatically whenever a stimulus is presented.

\section{Broader Implications}

In the preparation model, attentional control was accomplished by activating part of a structure. Activating the target set effectively "harnessed" the automatic processes of encoding and comparison so they would participate in activity directed toward producing a response. It may prove useful to distinguish points in the structure that attention can control from those that it cannot. The control points may well be the words of the language with which the mind talks to itself. Presumably, other control points must also be activated to assemble an appropriate structure, and each would contribute to the demands of the task. If a number of control points are consistently activated together, however, they may become associated so that activating one of them is enough to activate all of them. The development of automaticity might reflect the associative combination of control structures (cf. Experiment 1). Thus, the units of attention may be entire tasks as well as individual mental operations.
The dual role of attention in preparation and execution suggests a hierarchy of attentional control. In performing a task, capacity is first allocated to control structures to prepare the task as a whole for execution. Upon stimulus presentation, control may shift to the level of component operations; attention must be allocated to those operations (if any) that require it for execution. This shift is apparent in Comstock's (1975) data discussed earlier: Concurrent-probe reaction times were longer than single-task controls throughout the warning interval and the presentation of the first letter when the visual task could not have required attention for execution. This difference reflects the demands of maintaining a set to perform the visual task. When the second letter appeared, concurrent-probe reaction times increased sharply, but single-task controls did not. This further increase might reflect the additional demands of execution.

Finally, the emphasis on preparation and the maintenance of preparation is reminiscent of the notion of mental set in the early attention literature (see Woodworth, 1938). Attention literally sets the mind to respond in a certain way to particular aspects of stimulation. Stimulus presentation effectively releases the automatic processes comprising the set, and a response occurs without further attentional involvement. Historical antecendents may be found in discussions of the prepared reflex in the early introspective studies of reaction time (see Woodworth, 1938). Little of the reaction itself was found to be available to introspection, but the response to the instructions and the act of preparation preceding the reaction were readily available. The major cognitive involvement seemed to occur before the stimulus was presented, and the reaction itself seemed reflexive. Following Posner's speculative identification of capacity with consciousness (Posner \& Klein, 1972; Posner \& Snyder, 1975a), the evidence presented here for the automaticity of execution contrasted with the demanding nature of preparation echoes the earlier findings: Behavior in reaction time situations still appears to be nothing more than a prepared reflex. 


\section{Conclusions}

The experiments suggest that attention is best construed as the selective allocation of central processing capacity to activate mental structures, either individually or in concert as sets to perform a specific task. The automaticity of aspects of encoding, comparison, decision, and response-selection stages implicates preparation for the task as a whole as an important determinant of attention demands. The interactions between memoryload and target-set size provide some support for this view. Finally, the emphasis on mental set suggests that the most interesting things in visual search might go on before the array is presented.

\section{Reference Notes}

1. Posner, M. I., \& Keele, S. W. Time and space as measures of mental operations. Paper presented at the 78th Annual Meeting of the American Psychological Association, Miami Beach, Florida, September 1970.

2. Sternberg, S. Scanning a persisting visual image versus a memorized list. Paper presented at the 38th Annual Meeting of the Eastern Psychological Association, Boston, April 1967.

3. Neisser, U. Selective reading: A method for the study of visual attention. Paper presented at the XIX International Congress of Psychology, London, 1969.

\section{References}

Alluisi, E. A., Strain, G. S., \& Thurmond, J. B. Stimulus-response compatibility and the rate of gain of information. Psychonomic Science, 1964, $1,111-112$.

Anderson, J. A. A theory for the recognition of items from short memorized lists. Psychological Reviere, 1973, 80, 417-438.

Atkinson, R. C., Holmgren, J. E., \& Juola, J. F. Processing time as influenced by the number of clements in a visual display. Perception \& Psychophysics, 1969, 6, 321-326.

Atkinson, R. C., \& Shiffrin, R. M. Human memory: A proposed system and its control processes. In K. W. Spence \& J. T. Spence (Eds.), The psychology of learning and motivation: Advances in research and theory (Vol. 2). New York: Academic Press, 1968.

Baddcley, A. D., \& Ecob, J. R. Reaction-time and short-term memory: Implications of repetition effects for the high-speed exhausive scan hypothesis. Quarterly Journal of Experimental Psychology, 1973, 25, 229-240.
Becker, C. A. Allocation of attention during visual word recognition. Journal of Experimental Psychology: Human Perception and Performance, $1976,2,556-566$.

J Beller, H. K. Priming: Effects of advance information on matching. Journal of Experimental Psychology, 1971, 87, 176-182.

Bertelson, P. The time course of preparation. Quarterly Journal of Experimental Psychology, 1967, 19, 272-279.

Biederman, I., \& Kaplan, R. Stimulus discriminability and S-R compatability: Evidence for independent effects in choice reaction time. Journal of Experimental Psychology, 1970, 86, 434-439.

Briggs, G. E., \& Blaha, J. Memory retrieval and central comparison times in information processing. Joural of Experimental Psychology, 1969, $79,395-402$.

Briggs, G. E., \& Johnsen, A. M. On the nature of central processing in choice reations. Memory \& Cognition, 1973, 1, 91-100.

Briggs, G. E., \& Swanson, J. M. Encoding, decoding, and central functions in human information processing. Journal of Experimental Psychology, 1970, 86, 296-308.

Broadbent, D. E. Perception and communication. New York: Pergamon Press, 1958.

Broadbent, D. E., \& Gregory, M. Donders' Band $\mathrm{C}$ - reactions and $\mathrm{S}-\mathrm{R}$ compatibility. Journal of Experimental Psychology, 1962, 63, 575-578.

Broadbent, D. E., \& Gregory, M. On the interaction of $\mathrm{S}-\mathrm{R}$ compatibility with other variabics affecting reaction time. British Journal of Psychology, 1965, 56, 61-67.

Broadbent, D. E., \& Heron, A. Effects of a subsidiary task on performance involving immediate memory by younger and older men. British Journal of Psychology, 1962, 53, 189-198.

Brooks, L. R. Spatial and verbal components of the act of recall. Canadian Journal of Psychology, 1968, 22, 349-368.

Brown, J. Some tests of the decay theory of immediate memory. Quarterly Journal of Experimental Psychology, 1958, 10, 12-21.

Butler, B. Components of the familiarity effect in tachistoscopic recognition. Journal of Experimental Psychology, 1973, 101, 367-372.

Butler, B. The limits of selective attention in tachistoscopic recognition. Canadian Journal of Psychology, 1974, 28, 199-213.

Chow, S. L., \& Murdock, B. B., Jr. The effect of a subsidiary task on iconic memory. Memory $\&$ Cognition, 1975, 3, 678-688.

Chow, S. L., \& Murdock, B. B., Jr. Concurrent memory load and the rate of readout from iconic memory. Journal of Experimental Psychology: Human Perception and Performance, 1976, 2, 179-190.

Clifton, C., Cruse, D., \& Gutschera, K. D. Recoding processes in recognition: Some effects of presentation rate. Memory \& Cognition, 1973, 1, $387-394$. 
Comstock, E. M. Processing capacity in a lettermatch task. Journal of Experimental Psychology, 1973, 100, 63-72.

Comstock, E. M. Limited-capacity central attention mechanisms. Doctoral dissertation, University of Massachusetts, 1975.

Connor, J. M. Effects of increased processing load on parallel processing from visual displays. Perception \& Psychophysics, 1972, 12, 121-128.

Corballis, M. C. Access to memory: An analysis of recognition times. In P. M. A. Rabbitt \& S. Dornic (Eds.), Attention and performance $V$. New York: Academic Press, 1975.

Corballis, M. C., Roldan, C. E., \& Zbrodoff, J. Response set effects in recognition memory. Memory \& Cognition, 1974, 2, 501-508.

Crowder, R. G. Short-term memory for words with a perceptual-motor interpolated activity. Journal of Verbal Learning and Verbal Behavior, 1967, $6,753-761$.

Darley, C. F., Klatzky, R. L., \& Atkinson, R. C. Effects of memory load on reaction time. Journal of Experimental Psychology, 1972, 96, 232-234.

Deininger, R. L., \& Fitts, P. M. Stimulus-response compatibility, information theory, and perceptualmotor performance. In H. Quastler (Ed.), Information theory in psychology. Glencoe, Ill. Free Press, 1955.

Deutsch, J. A., \& Deutsch, D. Attention: Some theoretical considerations. Psychological Review, $1963,70,80-90$.

Dick, A. O. Parallel and serial processing in tachistoscopic recognition: Two mechanisms. Journal of Experimental Psychology, 1972, 96, 60-66.

Doost, R., \& Turvey, M. T. Iconic memory and ceniral processing capacity. Perception $\&$ Psychophysics, 1971, 9, 269-274.

Dyer, F. N. The Stroop phenomenon and its use in the study of perceptual, cognitive, and response processes. Memory \& Cognition, 1973, 1, $106-120$.

Egeth, H. Attention and preattention. In G. H. Bower (Ed.), The psychology of learning and motivation (Vol. 11). 1977.

Egeth, H., Atkinson, J., Gilmore, G., \& Marcus, N. Factors influencing processing mode in visual search. Perception \& Psychophysics, 1973, 13, 394-402.

Estes, W. K. Interactions of signal and background variables in visual processing. Perception $\mathcal{F}$ Psychophysics, 1972, 12, 278-286.

Estes, W. K. Redundancy of noise elements and signals in visual detection of letters. Perception \& Psychophysics, 1974, 16, 53-60.

Estes, W. K. Memory, perception and decision in letter identification. In R. L. Solso (Ed.), Information processing and cognition: The Loyola symposium. Hillsdale, N.J.: Erlbaum, 1975. (a)

Estes, W. K. Structural aspects of associative models for memory. In C. N. Cofer (Ed.), The structure of human memory. San Francisco: Freeman, 1975. (b)
Estes, W. K., \& Taylor, H. A. A detection method and probabilistic models for assessing information processing from brief visual displays. Proceedings of the National Academy of Science, $1964,52,446-454$.

Estes, W. K., \& Wesse1, D. C. Reaction time in relation to display size and correctness of response in forced-choice visual signal detection. Perception \& Psychophysics, 1966, 1, 369-373,

Gardner, G. T. Evidence for independent channels in tachistoscopic perception. Cognitive Psychology, 1973, 4, 130-155. (a)

Gardner, G. T. Parallel perceptual processing and decisional strategies: A reinterpretation of the Shaw and LaBerge effect. Perception \& Psychophysics, 1973, 13, 517-518. (b)

Gottsdanker, R. The attaining and maintaining of preparation. In P. M. A. Rabbitt \& S. Dornic (Eds.), Attention and performance $V$. New York: Academic Press, 1975.

Graboi, D. Searching for largets: The effects of specific practice. Perception \& Psychophysics, $1971,10,300-304$.

Hawkins, H. L., MacKay, S. L., Holley, S. L., Friedin, B. D., \& Cohen, S. L. Locus of the relative frequency effect in choice reaction time. Joumal of Experimental Psychology, 1973, 101, 90-99.

Henderson, L. Spatial and verbal codes and the capacity of STM. Quarterly Joumal of Experimental Psychology, 1972, 24, 485-495.

Holmgren, J. E. The effect of a visual indicator on rate of visual search: Evidence for processing control. Perception \& Psychophysics, 1974, 15, 544-550. (a)

Holmgren, J. E. Visual search in a forced-choice paradigm. Perception \& Psychophysics, 1974, 16, 253-258. (b)

Howard, J. H. The attentional demands of negation in a memory-scanning lask. Memory $\& \mathrm{Cog}$ nition, 1975, 3, 319-324.

Johnsen, A. M., \& Briggs, G. E. On the locus of display load effects in choice reactions, Journal of Experimental Psychology, 1973, 99, 266-271.

Johnston, W. A., Greenberg, S. N., Fisher, R. P., \& Martin, D. W. Divided attention: A vehicle for monitoring memory processes. Journal of Experimental Psychology, 1970, 83, 164-171.

Kahneman, D. Remarks on attentional control. Acta Psychologica, 1970, 33, 118-131.

Kahneman, D. Attention and effort. Englewood Cliffs, N.J.: Prentice-Hall, 1973.

Keele, S. W. Compatibility and time-sharing in serial reaction time. Joumal of Eixperimental Psychology, 1967, 75, 529-539.

Keele, S. W. Attention demands of memory retrieval. Journal of Experimental Psychology, 1972, 93, 245-248.

Keele, S. W. Attention and human performance. Pacific Palisades, Calif.: Goodyear, 1973.

Keren, G. Some considerations of two alleged kinds of selective attention. Journal of Experimental Psychology: General, 1976, 105, 349-374. 
Kolers, P. A. Memorial consecuences of automalized encoding. Journal of Experimental Psychology: IImman Learning and Menory, 1975, 1, 689-701.

Kristofferson, M. W. Effects of practice on character classification performance. Canadian Journal of Psychology, 1972, 26, 54-60. (a)

Kristofferson, $M$. W. When item recognition and visual scarch functions are similar. Perception \& Psychophysics, 1972, 12, 379-384. (b)

LaBerge, D. Identification of two components of the time to switch attention: $\Lambda$ test of a serial and a parallel model of attention. In S. Kornblum (Ecl.), Attention and performance $I V$. New York: Academic Press, 1973. (a)

LaBerge, D. Attention and the measurement of perceptual learning. Memory \& Cognition, 1973, 1. 268-276. (b)

LaBerge, D., \& Samucls, S. J. Toward a theory of automatic information processing in reading. Cognitive Psychology, 1974, 6, 293-323.

Logan, G. D. On the nature of capacity limitations in visual search. Doctoral dissertation, McGill University, 1975.

Logatr, G. D. Converging evidence for automatic perceptual processing in visual search. Canadian Journal of Psychology, 1976, 30, 193-200.

Logan, G. I)., Withey, M. J., \& Cowan, W. B. Cuc search and comparison processes in visual search for letters. Canadian Journal of Psychology, 1977, 31, 113-121.

Mewhort, 1). J. K. Familiarity of letter sequences, response uncertainty and the tachistoscopic recognition experiment. Canadian Joumal of Psychology, 1967, 21, 309-321.

Millar, K. Processing capacity requirements of stimulus encoding. Acta Psychologica, 1975, 39, $393-410$

Moray, N. Where is capacity limited? A survey and a model. Acta Psychologica, 1967, 27, 84-92.

Neisser, U. Decision-time without reaction-time: Experiments in visual scanning. American Journal of Psychology, 1963, 76, 376-385.

Neisser, U. Cognitive psychology. New York: Appleton-Century-Crofts, 1967.

Neisser, U. Practiced card sorting for multiple targets. Memory \& Cognition, 1974, 2, 781-785.

Neisser, U., Novick, R., \& Lazar, R. Searching for ten targets simultancously. Perceptual and Motor Skills, 1963, 17, 955-961.

Nickerson, R. S. Response times with a memorydependent decision task. Journal of Experimental Psychology, 1966, 72, 761-769.

Nickerson, R. S. Binary-classification reaction time: A revicw of some studies of human information-processing capabilities. Psychonomic Monograph Supplements, 1972, 4, 275-318.

Norman, D. A., \& Bobrow, D. G. On data-limited and resource-limited processes. Cognitive Psychology, 1975, 7, 44-64.

Novik, N., \& Katz, L. High-speed visual scanning of words and nonwords. Journal of Experimental Psychology, 1971, 91, 350-353.
Pachella, R. G. The interpretation of reaction time in information-processing research. In $\mathrm{B}$. $\mathrm{H}$. Kantowitz (Ed.), Human information processing: Tutorials in performance and cognition. Hillsdale, N.J.: Erlbaum, 1974.

Peterson, L. R. Concurrent verbal activity. Psychological Review, 1969, 76, 376-386.

Peterson, L. R., \& Peterson, M. J. Short-term retention of individual verbal items. Journal of Experimental Psychology, 1959, 58, 193-198.

Posner, M. I., \& Boies, S. J. Components of attention. Psychological Revieze, 1971, 78, 391408.

Posner, M. I., \& Klein, R. On the functions of consciousness. In S. Kornblum (Ed.), Attention and performance IV. New York: Academic Press, 1973.

Posner, M. I., \& Rossman, E. Effect of size and location of informational transforms upon shortterm retention. Joumal of Experimental Psychology, 1965, 70, 496-505.

Posner, M. I., \& Snyder, C. R. R. Attention and cognitive control. In R. I. Solso (Ed.), Information processing and cognition: The Loyola symposium. Hillsdale, N.J.: Erlbaum, 1975. (a)

Posner, M. I., \& Snycler, C. R. R. Facilitation and inhibition in the processing of signals. In P. M. A. Rabbitt \& S. Dornic (Eds.), Attention and performance $V$. New York: Academic Press, 1975. (b)

Rabbitt, P. M. A. Signal discriminability, S-R compatibility and choice reaction time. Psychonomic Science, 1967, $7,419420$.

Rosch, E. Cognitive representations of semantic categories. Journal of Experimental Psychology: Gencral, 1975, 104, 192-233.

Rosch, E., Simpson, C., \& Miller, R. S. Structural bases of typicality effects. Journal of Isxperimental Psychology: Human Perception and Performance, 1976, 2, 491-502.

Rumelhart, D. E. A multicomponent theory of the perception of briefly exposed visual displays. Journal of Mathematical Psychology, 1970, 7, 191-218.

Salthouse, T. A. Simultaneous processing of verbal and spatial information. Menory \& Cognition, $1975,3,221-225$.

Scarborough, D. L. Memory for brief visual displays of symbols. Cognitioc Psychology, 1972, 3, 408-429.

Schneider, W., \& Shiffrin, R. M. Controlled and automatic human information processing: I. Detection, search, and attention. Psychological Review, 1977, 84, 1-66.

Shiffrin, R. M., \& Geisler, W. S. Visual recognition in a theory of information processing. In R. L. Solso (Ed.), Contemporary issues in cognitive psychology: The Loyola symposium. Washington, IJ.C. : Winston, 1973.

Shiffrin, R. M., \& Schneider, W. Controlled and automatic human information processing: II. Perceptual learning, attomatic attending, and a general theory. I'sychological Review, 1977, 84, $127-190$. 
Shulman, H. G., \& Greenberg, S. N. Perceptual deficit due to division of attention between memory and perception. Journal of Experimental Psychology, 1971, 88, 171-176.

Shulman, H. G., Greenberg, S. N., \& Martin, J. Intertask delay as a parameter of perceptual deficit in divided attention. Jomrnal of Experimental Psychology, 1971, 88, 439-440.

Smith, E. E. Choice reaction time: An analysis of the major theoretical positions. Psychological Bulletin, 1968, 69, 77-110.

Sternberg, S. 'Two opcrations in character recognition: Some evidence from reaction-time measurements. Perception \& Psychophysics, 1967, 2, $45-53$.

Sternberg, S. The discovery of processing stages: Extensions of Donders' method. In W. G. Koster (Ed.), Attention and performance II. Amsterdam: North Holland, 1969. (a)

Sternberg, S. Memory scanning: Mental processes revealed by reaction-time experiments. American Scicntist, 1969, 57, 421-457. (b)

Sternberg, S. Memory scanning: New findings and current controversies. Quarterly Journal of Experimental Psychology, 1975, 27, 1-32.

Stroop, J. R. Studies of interference in serial verbal reactions. Jonrnal of Experimental Psychology, 1935, 18, 643-662.

Taylor, D. A. Stage analysis of raction time. Psychological Bulletin, 1976, 83, 161-191.

Thomas, E. A. C. The selectivity of preparation. Psychological Review, 1974, 81, 442-464.

Thorndike, E. L., \& Lorge, T. The teacher's word book of 30,000 words. New York: Columbia
University, Teachers College, Bureau of Publications, 1944.

Townsend, J. T., \& Roos, R. N. Search reaction time for single targets in multiletter stimuli with brief visual displays. Menory $\mathcal{E}$ Cognition, 1973, 1, 319-3.32.

Treisman, A. M. Strategies and models of selective attention. Psychological Review, 1969, 76, 282299.

Turvey, M. T. The effects of rehearsing analyzed information upon the retrieval of unanalyzed information. Psychonomic Scicnce, 1966, 6, 365366.

Watkins, M. J., Watkins, O. C., Craik, F. I. M., \& Mazuryk, C. Effect of nonverbal distraction on short-term storage. Journal of Experimental Psychology, 1973, 101, 296-300.

Wattenbarger, B. I.., \& Pachella, R. G. The effect of memory load on reaction time in character classification. I'crception \& P'sychophysics, 1972, 12, 100-102.

Welford, A. T. Fundamentals of skill. London: Methuen, 1968.

Willows, D. M. Reading between the lines: Selective attention in good and poor readers. Child Development, 1974, 45, 408-415.

Willows, D. M., \& MacKinnon, G. E. Selective reading: Attention to the "unattended" lines. Canadian Joumal of Psychology, 1973, 27, 292304.

Woodworth, R. S. Experinental psychology. New York: Holt, 1938.

Received September 23, 1976 